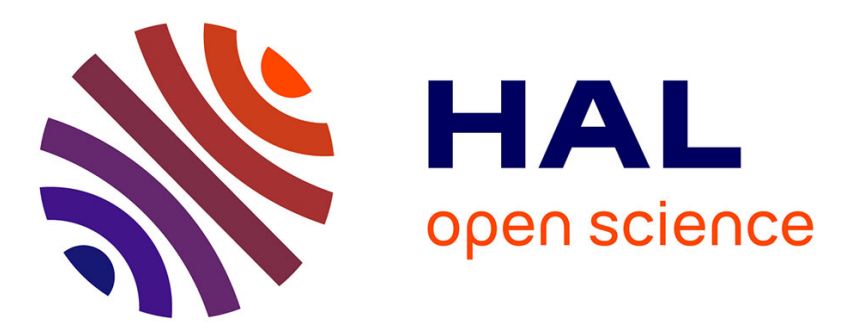

\title{
An empirical correlation for the relative permittivity of liquids in a wide temperature range: application to the modeling of electrolyte systems with a GE/EoS approach.
}

\author{
Isabelle Raspo, Evelyne Neau
}

\section{To cite this version:}

Isabelle Raspo, Evelyne Neau. An empirical correlation for the relative permittivity of liquids in a wide temperature range: application to the modeling of electrolyte systems with a GE/EoS approach.. Fluid Phase Equilibria, 2020, 506, pp.112371. 10.1016/j.fluid.2019.112371 • hal-02325903

\section{HAL Id: hal-02325903 \\ https://hal.science/hal-02325903}

Submitted on 4 Dec 2019

HAL is a multi-disciplinary open access archive for the deposit and dissemination of scientific research documents, whether they are published or not. The documents may come from teaching and research institutions in France or abroad, or from public or private research centers.
L'archive ouverte pluridisciplinaire HAL, est destinée au dépôt et à la diffusion de documents scientifiques de niveau recherche, publiés ou non, émanant des établissements d'enseignement et de recherche français ou étrangers, des laboratoires publics ou privés. 


\title{
An empirical correlation for the relative permittivity of liquids in a wide temperature range: application to the modeling of electrolyte systems with a $\mathbf{G}^{\mathbf{E}} / \mathbf{E o S}$ approach
}

\author{
Isabelle Raspo*, Evelyne Neau \\ Aix Marseille Univ, CNRS, Centrale Marseille, M2P2, Marseille, France
}

\begin{abstract}
Relative permittivity, also known as static dielectric constant, is a key property of solvents in electrolyte solutions. It strongly influences the solubility of solutes and, therefore, it can be used as a predictive tool in chemical engineering processes. Relative permittivity also plays an essential role in the modeling of phase equilibria of electrolyte systems, since it is involved in the Debye-Hückel model and in the Mean Spherical Approximation, commonly used to represent long-range interactions between ions. In this paper, we propose a new temperature-dependent correlation for the relative permittivity of liquid water, methanol and ethanol, valid in a wide temperature range, including very high temperatures. Comparison with other literature equations evidenced that the main interest of the proposed correlation is to allow satisfactory predictions of the relative permittivity, not only in the range of validity of other literature models, but also in the high temperature domain, including supercritical temperatures for water. The new correlation is then used with the NRTL-PRA EoS to predict vapor pressure of water with several salts, including single electrolytes and two-salts mixtures; it must be noted that the modeling presented in this work is relevant for any $G^{\mathrm{E}} / \mathrm{EoS}$ model, since in this case (binary interactions between water and ions being equal to zero), the excess Gibbs energy reduces to the Long-Range term derived from the Pitzer-Debye-Hückel model. A temperaturedependent correction of the solvent relative permittivity is proposed to account for its dependence on ion mole fraction in this Long-Range term. Results thus obtained show that this correction leads to an accurate prediction both: for vapor pressures of aqueous electrolyte solutions in a very wide temperature domain and for the modeling of vapor-liquid equilibria of methanol-water and ethanolwater mixtures with several salts.
\end{abstract}

Key words: relative permittivity, electrolytes, $G^{\mathrm{E}} /$ EoS approach, phase equilibria, NRTL-PRA EoS

\section{1- Introduction}

Electrolyte systems are involved in many industrial applications and natural processes. We can cite, among many others, offshore petroleum exploitations, precipitation and crystallization processes, water treatment and production of fertilizers. In nature, electrolytes play a substantial role in many geothermal systems and biological processes for living organisms such as, for example, transmission and conduction of nerve impulses in human body. For electrolyte solutions, the static dielectric constant, also known as relative permittivity, is an essential physical property of the solvent since it is a measure of its capability to separate electrolyte into ions: solvents with a high relative permittivity, such as water, lead to complete dissociation of the electrolyte. The relative permittivity of the solvent strongly influences the behavior of electrolytes in solutions; in particular, it directly affects the 
solubility of the solute [1] and therefore it can be used to predict this property by means of theoretical equations [1,2] or empirical correlations $[3,4]$. Consequently, equations for relative permittivity are of great interest for chemical engineering processes. The dielectric constant also plays an essential role in the modeling of phase equilibria of electrolyte systems. Indeed, although an abundance of models was proposed in literature for phase equilibria (LIQUAC [5, 7], LIFAC [6, 7], e-NRTL [8, 9], PSRKLIFAC [10], VTPR-LIFAC [11], e-CPA [12], e-PC SAFT [12], SAFT-VRE [13, 14], SAFT-VR Mie [15], NRTL-PRA [16]...), all these models account for ion-ion interactions by means of a long-range term derived from the Debye-Hückel model [17] or the Mean Spherical Approximation (MSA) [18,19]. Both of these long-range interaction models involve the relative permittivity of the solvent. Therefore, the equation used for the static dielectric constant directly affects the accuracy of the phase equilibria representation.

Several equations were developed in literature for the calculation of the relative permittivity of polar liquids. Some of them [20, 21] are based on theories such as the Onsager [22] and Kirkwood theories [23]. Many empirical correlations were also proposed to represent the dependence on temperature [16, 24-30] and/or on density [14, 15, 31, 32]. However, except for those developed in [24] for ethanol and in [26] for water, these correlations are limited to temperatures lower than 400K. Moreover, density-dependent expressions increase complexity when they are used in $\mathrm{G}^{\mathrm{E}} /$ EoS models.

In this paper, the temperature dependent correlation presented in [16] is extended to a wide temperature range by fitting the parameters on a large data base including temperatures up to $823 \mathrm{~K}$ for water and more than $500 \mathrm{~K}$ for methanol and ethanol. Considering temperatures above the critical point of water leads to a correlation suitable for chemical engineering processes involving supercritical water such as, for instance, Supercritical Water Oxidation [33], for which salt solubility is of great interest. Results obtained for the relative permittivity are compared with those provided by literature correlations. The new correlation is then used with the NRTL-PRA equation of state for the prediction of vapor pressure of water with several salts and the modeling of vapor-liquid equilibria in methanolwater and ethanol-water mixtures. It must be noted that the results for vapor pressure of aqueous electrolytes are relevant for any $\mathrm{G}^{\mathrm{E}} / \mathrm{EoS}$ model, since in this case, binary interactions between water and ion being equal to zero, the excess Gibbs energy reduces to the Long-Range term derived from the Pitzer-Debye-Hückel model [34].

\section{2- A temperature dependent correlation for the relative permittivity of liquids for a wide temperature range}

In [16], Neau et al. presented the correlation developed by Neau and Raspo [35] for the representation of the relative permittivity of polar compounds with respect to temperature:

$$
\varepsilon_{r}(T)=A_{0}+A_{1} T+A_{2} T^{2}+A_{4} / T+A_{5} \operatorname{Ln}(T)
$$

However, the parameters were fitted on "data" generated from CRC Handbook correlations valid only for temperatures lower than $400 \mathrm{~K}$. In the present paper, we considered a large database including temperatures up to $823 \mathrm{~K}$ for water, $525 \mathrm{~K}$ for methanol and $513 \mathrm{~K}$ for ethanol (see Table 1 ). The objective was to obtain simultaneously similar results to those given by literature correlations in the temperature range where they are defined and an accurate representation of the relative permittivity in the high temperature domain; it is worth recalling that the comparison between experimental and calculated data should be performed in the limits of experimental uncertainties (about 1\%-3\% for temperatures larger than $400 \mathrm{~K})$. The fitted parameter values are reported in Table 2.

In order to evaluate the new correlation, a comparison was performed with literature models. Since we wanted to use the same correlation for all the compounds, the equations proposed by Fernández et 
al. [26] and Tan et al. [27] especially for water were not considered in this study. Therefore, the new correlation was compared with those given in the CRC Handbook of Chemistry and Physics [24] and by Zuo and Fürst [25], Zuber et al. [29] and Chunxi and Fürst [30], respectively defined by:

$$
\begin{aligned}
& \varepsilon_{r}(T)=A_{0}+A_{1} T+A_{2} T^{2}+A_{3} T^{3} \\
& \varepsilon_{r}(T)=A_{0}+A_{1} T+A_{2} T^{2}+A_{3} T^{3}+A_{4} / T
\end{aligned}
$$

The values of parameters $A_{i}$ in Eqs. (2) and (3), together with those given in [16] for Eq. (1), are reported in Table 3; the temperature range of validity of each equation is also indicated, except for Eq. (1) with parameters of [16] (indeed, as specified at the beginning of this section, these parameters were fitted only on data "generated" from literature correlations and their "extrapolation" toward temperatures up to $650 \mathrm{~K})$. For the sake of clarity, the following notations are used hereinafter:

- NR correlation: Eq. (1) with parameters given in [16],

- CRC correlation: Eq. (2) with parameters of [24],

- ZZC correlation: Eq. (3) with parameters of [25] for water and ethanol and [29] for methanol.

Table 4 presents the mean relative deviations obtained with the various correlations for the different temperature ranges of validity of literature correlations and in the high temperature domain. It can be noted that:

- As expected, all correlations give satisfactory results in their temperature range of validity; but the new correlation is the only one which provides excellent results for all compounds, whatever the temperature range considered.

- Concerning the other literature models in the high temperature domain, we observe that the NR correlation, also derived from Eq. (1), leads to less bad results in this domain. For ethanol, deviations given by the CRC correlation are quite similar, since these data also belonged to the range of validity (Table 3). Except this case, huge errors are obtained with the CRC and ZZC correlations.

Above results are also illustrated in Fig. 1: only the new correlation is able to provide, for the three compounds, an accurate representation of experimental data in the whole range of temperatures; results obtained with the NR correlation are obviously much less satisfactory; concerning models derived from the other equations: the ZZC correlation (Eq. (3)) gives the worst and totally false evolution of $\varepsilon_{r}$ for temperatures larger than $350 \mathrm{~K}$ for alcohols and $500 \mathrm{~K}$ for water; a rather similar behavior is also observed with the CRC correlation (Eq. (2)) for water and methanol.

In order to check, as for Eq. (1), the capability of Eqs. (2) and (3) to describe the behavior of relative permittivity at high temperatures, parameters $A_{i}$ of these two equations were fitted on the database of Table 1. Resulting curves are presented in Fig. 2 together with those provided by our new correlation. The parameter fitting obviously improves the representation of relative permittivity; however, an incorrect variation is still observed for very high temperatures $(T>650 \mathrm{~K}$ for water, and $T>520 \mathrm{~K}$ for alcohols).

As a conclusion, results presented herewith evidence: first, that the use of literature models, CRC and ZZC, should be restricted to modelings in their validity domain; second, that the new correlation is the only one suitable for an accurate prediction of the relative permittivity, not only in the range of validity of literature models, but also in the high temperature domain.

\section{3- Application to phase equilibria of electrolyte systems with a $\mathrm{G}^{\mathrm{E}} / \mathrm{EoS}$ model}

In this work, we considered the NRTL-PRA EoS [36], based on the Peng-Robinson equation of state [37] and the generalized NRTL G ${ }^{\mathrm{E}}$ model [38], modified in [16] to account for electrolytes. Table 
5 resumes the general expressions of the compressibility factor $Z$ and the excess Gibbs energy $g_{\text {EoS }}^{E}$ for electrolytes; appendices A and B successively describe the estimation of the pure component parameters $a_{i}$ and $b_{i}$ and the binary interaction parameters $\Gamma_{j i}$ with respect to the model group contribution parameters [39], $Q_{k}$ and $\Gamma_{L K}$ (respectively reported in Tables 6 and $7 \mathrm{a}, 7 \mathrm{~b}$ and $7 \mathrm{c}$ ).

The purpose of this section is to extend, by means of the NRTL-PRA equation [16], the use of the new correlation, proposed for the relative permittivity, to the prediction of vapor pressure of aqueous electrolyte solutions and to the modeling of vapor-liquid equilibria in methanol-water and ethanolwater mixtures with salts.

\section{1- Prediction of the vapor pressure of aqueous electrolyte solutions}

In the case of aqueous electrolyte solutions, since binary interaction parameters $\Gamma_{L K}$ between water and ions are equal to zero (Tables 7), the excess Gibbs energy $g_{E o S}^{E}$ (Table 5) reduces to the long-range term $g_{L R}^{E}$ derived from the Pitzer-Debye-Hückel model [34]:

$$
g_{E o S}^{E}=g_{L R}^{E}=-R T\left[\frac{4 A_{x} I_{z}}{\chi} \ln \left(1+\chi \sqrt{I_{z}}\right)\right]
$$

Consequently, results obtained in this section are of general interest for any $\mathrm{G}^{\mathrm{E}} / \mathrm{EoS}$ model based on the same long-range term to account for ion-ion interactions.

The new correlation was used in the estimation of the solvent permittivity $\varepsilon_{r}^{*}$, involved in the expression of $g_{L R}^{E}$ in Table 5, to predict the vapor pressure of water with 6 single salts and 4 mixed electrolytes (Table 8). It can be noted that, except for $\mathrm{NaCl}, \mathrm{KCl}$ and $\mathrm{LiBr}$, experimental data are only available for temperatures lower than $400 \mathrm{~K}$. Moreover, except for $\mathrm{LiCl}$ and $\mathrm{LiBr}$, the maximum molality does not exceed 10.5. The analysis of preliminary results obtained by means of the new correlation led to the following conclusions:

- First: results obtained with the NR and the new correlations were compared for the modelling of the system $\mathrm{H}_{2} \mathrm{O}-\mathrm{NaCl}$ (Figs. 3a-3d). As shown in Figs. 3a and 3c:

- both modelings overestimate the vapor pressure for temperatures lower than $450 \mathrm{~K}$, but they exhibit different trends in the high-temperature range $(T>450 \mathrm{~K})$ : the NR correlation overestimates $P_{\text {vap }}$ for all the molalities (Fig. 3b), while the new correlation leads to satisfactory predictions in the whole temperature range for $m=1$ and up to $T=525 \mathrm{~K}$ for $m=3$ and $m=6$.

- however, for larger temperatures (Fig. 3d), the new correlation underestimates $P_{v a p}$ and this underestimation increases with increasing values of $m$.

- Second: since the binary interaction parameters $\Gamma_{\mathrm{H}_{2} \mathrm{O} / \mathrm{Na}^{+}}$and $\Gamma_{\mathrm{H}_{2} \mathrm{O} / \mathrm{Cl}^{-}}$are set to zero in the original model [16] (Tables 7), we have "tried" to improve the modeling by fitting these parameters to the experimental vapor pressure data of $\mathrm{H}_{2} \mathrm{O}-\mathrm{NaCl}$ (Table 8). Results obtained by fitting parameters in the low-temperature range $(T<450 \mathrm{~K})$ and predicting in the high-temperature range $(T>450 \mathrm{~K})$, and conversely, are summarized in Fig. 4. The following conclusions can be drawn:

- Figures $4 \mathrm{a}$ and $4 \mathrm{~d}$ reveal that the fitting of parameters leads to quite satisfactory representations in the corresponding temperature range. However, in both cases, Figs. $4 \mathrm{~b}$ and $4 \mathrm{c}$, clearly show that the predictions of vapor pressures in the other temperature range are strongly deteriorated. 
- Moreover, the values of the fitted parameters are very different for the two temperature domains (Fig. 4). This proves that vapor pressures cannot be modeled with a single set of parameters in the whole domain; therefore, the binary interaction parameters $\Gamma_{\mathrm{H}_{2} \mathrm{O} / \mathrm{Na}^{+}}$and $\Gamma_{\mathrm{H}_{2} \mathrm{O} / \mathrm{Cl}^{-}}$were maintained to zero.

- Third: the bad results obtained with increased molalities in Fig. 3d suggest that ion mole fraction should be taken into account in the solvent permittivity $\varepsilon_{r}^{*}$ as was recommended in particular by Maribo-Mogensen et al. [86]. Indeed:

- it is known that the presence of salt leads to a decrease of the solvent relative permittivity (even if this observation was usually done for temperatures lower than $400 \mathrm{~K})$. According to equations of Table 5, a decrease of $\varepsilon_{r}^{*}$ induces an increase of parameter $A_{x}$ and, consequently, an overestimation of the vapor pressure, as observed in Figs. $3 \mathrm{a}$ and $3 \mathrm{c}$ for temperatures lower than $450 \mathrm{~K}$.

- On the other hand, the underestimation of $P_{v a p}$ for high temperatures with the new correlation suggests an increase of $\varepsilon_{r}^{*}$ for increasing molalities. This behavior is quite surprising, but it is in agreement with results of Gavish and Promislow [87] and Walther and Schott [88]. Indeed, the former showed that the decrease of the relative permittivity of aqueous solution of $\mathrm{NaCl}$ depends on temperature, since it is less important for molalities larger than 4 as temperature increases [87]. Moreover, according to the study of Walther and Schott [88] it also appears that, for aqueous solution of $\mathrm{KCl}$, the relative permittivity increases at high temperatures by addition of $\mathrm{KCl}$.

So, as proposed in [86] and [89], we introduced a correction factor $E$ in the solvent relative permittivity $\varepsilon_{r}^{*}$ to account for the dependence on ion mole fraction:

$$
\varepsilon_{r}^{*}=\left(\sum_{i=1}^{p_{S F}} x_{S F_{i}} b_{i} \varepsilon_{r_{i}} / v^{*}\right) E
$$

with:

$$
E=E\left(T, x_{i o n}\right)=1+\delta(T) \sum_{k=1}^{p_{\text {ion }}}\left(10^{-5} \frac{x_{k}}{v^{*}}-\frac{\alpha_{k} x_{k} / v^{*}}{1+1.60 \times 10^{-4} x_{k} / v^{*}}\right)
$$

and:

$$
\delta(T)=0.6 \text { th }(0.02(498.15-T))
$$

Equation (6) shows that the temperature-independent formula of [86] and [89] has been modified to account for the dependence on temperature by introducing the function $\delta$; this function was determined so that $\varepsilon_{r}^{*}$ decreases for low temperatures and increases for temperatures larger than $500 \mathrm{~K}$. For the ion specific parameter $\alpha_{k}$ (Eq. (6)), the values (Table 9) proposed by Maribo-Mogensen et al. [86] and Michelsen and Mollerup [89] were used, except for $\mathrm{Li}^{+}$, which needed a specific estimation.

Always for the system $\mathrm{H}_{2} \mathrm{O}-\mathrm{NaCl}$, Figures 5.a and 5.b show that this temperature dependent correction factor really provides accurate prediction of the vapor pressures for both low and high temperature ranges.

The influence of the new correlation of the solvent relative permittivity $\varepsilon_{r}^{*}$, with (Eq. (5)) or without (Table 5) the correction factor $E$ (Eq. (6)) was then checked on the set of aqueous electrolyte solutions reported in Table 8 . Results obtained for molalities $m$ smaller than 10, which concerns the 
major part of literature data, are presented in Tables 10 and 11. The analysis of results led to the following conclusions:

- For single salts, with molalities less than 10 (Table 10), the correction factor $E$ strongly improves the prediction of vapor pressure in the low-temperature range $(T<450 \mathrm{~K})$ for all the electrolytes, with deviations usually less than $6 \%$. The strongest improvements are obtained for $\mathrm{LiCl}, \mathrm{NaBr}$ and $\mathrm{LiBr}$, since these three salts exhibit the largest maximum molality $\left(m_{\max } \approx 9.5\right)$ and, consequently, the most important influence of $x_{\text {ion }}$ on $\varepsilon_{r}^{*}$.

- Always in Table 10, but in the high-temperature range $(T>450 \mathrm{~K})$ that concerns only three salts, results are also really improved by the correction factor for $\mathrm{NaCl}$ and $\mathrm{KCl}$, even if for $\mathrm{LiBr}$ deviations remain too large.

- Even for smaller values of $m$, results are really improved by the introduction of the correction factor, as for $\mathrm{KBr}$ in Table 10 or for mixed electrolytes in Table 11. In both cases, deviations obtained without the factor $E$ are rather small, even if the vapor pressure is still overestimated, as described in Figs. $6 a$ and $7 \mathrm{a}$; as shown in Figs. $6 \mathrm{~b}$ and $7 \mathrm{~b}$, much better results are obtained thanks to the introduction of the correction factor $E$.

Results obtained for higher molalities $(m>10)$ are presented in Table 12. For the four electrolytes concerned, vapor pressure estimations are highly improved by the introduction of the correction factor $E$, even if, obviously, deviations remain much larger than those previously obtained for $m<10$ (especially for $\mathrm{LiBr}$ with an error of $95 \%$ in the high-temperature range).

\section{2- Representation of vapor-liquid equilibria in alcohol-water-salts systems}

This section focuses on the modeling of vapor-liquid equilibria of methanol-water and ethanolwater mixtures with several salts by means of the NRTL-PRA EoS (Table 5) with $\varepsilon_{r}^{*}$ calculated by Eq. (5). As specified in [36], mixtures containing only associating components (as methanol, ethanol and water) are assumed to be miscible mixtures, it means without phase splitting, and in this case $g_{\text {diss }}^{E}=0$; this assumption was extended to ions in [16]. So, for methanol-water and ethanol-water mixtures with salts, the excess Gibbs energy only contains the Short-Middle-Range term $g_{S M R}^{E}$ and the Long-Range term $g_{L R}^{E}$ :

$$
g_{E O S}^{E}=g_{S M R}^{E}+g_{L R}^{E}
$$

In this work, the interaction parameters between alcohol groups $\mathrm{OH}(o l 1), \mathrm{OH}(o l 2)$ and ions in $g_{S M R}^{E}$ were fitted on literature data of Table 13; the corresponding new values of parameters $\Gamma_{L K}$ are reported in Tables 7.

Results of the modeling of vapor-liquid equilibria are reported in Table 13 and illustrated, respectively, in Figs. 8 and 9 where phase equilibria are represented with respect to the salt-free mole fraction $x_{1}$ of alcohol. It must be noted that:

- Experimental data only concern low pressures $(P \leq 1$ bar $)$ and temperatures below $400 \mathrm{~K}$, where Eq.

(5) leads to a decrease of the solvent relative permittivity.

- Table 13 reveals that, apart from mixtures methanol-water- $\mathrm{NaBr}$ and ethanol-water-LiCl, the NRTL-PRA EoS provides a satisfactory representation of VLE for all mixtures, with deviations on pressure lower than $5 \%$ for isothermal data and, at most, about $1 \%$ for isobaric data for all mixtures. These results are confirmed by Figs. 8.a-8.c and Figs. 9.a-9.b. 
- Concerning mixtures with $\mathrm{NaBr}$ (Fig. 8.d) and $\mathrm{LiCl}$ (Fig. 9.c), for which higher deviations are observed in Table 13, both figures show, however, that, even for these two systems, phase equilibria are correctly described up to $m_{s}=4$ for methanol-water- $\mathrm{NaBr}$ and up to $m_{s}=1$ for ethanol-water$\mathrm{LiCl}$.

The group parameters $\Gamma_{L K}$ of Tables 7, fitted on data of Table 13, were then used for the prediction of VLE for the methanol-water system with two-salts mixtures. As shown in Table 14, the NRTL-PRA EoS provides very satisfactory results for the three systems considered.

\section{4- Conclusion}

In this paper, we proposed a new empirical temperature-dependent correlation for the relative permittivity of liquid water, methanol and ethanol, valid in a wide temperature range including temperatures up to $823 \mathrm{~K}$ for water and more than $500 \mathrm{~K}$ for methanol and ethanol. Results obtained with this new equation were compared with those provided by several literature correlations ([16], [24], [25], [29]). They showed that, contrary to other correlations, our model allows an accurate representation of the relative permittivity, not only in the range of validity of literature models, but also in the high temperature domain.

The new correlation was then used in a $\mathrm{G}^{\mathrm{E}} / \mathrm{EoS}$ model, the NRTL-PRA EoS ([36], [16]), to predict vapor pressure of water with several salts, including single electrolytes and two-salts mixtures. As binary interaction parameters of the NRTL-PRA EoS between water and ions are equal to zero, results obtained in this work are relevant for any $\mathrm{G}^{\mathrm{E}} / \mathrm{EoS}$ model, since the excess Gibbs energy reduces to the Long-Range term derived from the Pitzer-Debye-Hückel model [34]. A preliminary study on the water$\mathrm{NaCl}$ system revealed the necessity to take into account ion mole fraction in the solvent permittivity of the Pitzer-Debye-Hückel term. However, contrary to the decrease usually observed at low temperatures, an increase of the relative permittivity of the solvent with increasing salt molality was obtained for temperatures larger than $450 \mathrm{~K}$. Consequently, we developed a temperature-dependent correction term by modifying the temperature-independent version originally proposed by MariboMogensen et al. [86] and Michelsen and Mollerup [89]. We showed that this correction term leads to an accurate prediction of vapor pressures of aqueous electrolyte solutions, both in the low temperature and high temperature domains for molalities lower than 10.

Finally, the NRTL-PRA EoS with the new correlation and the temperature-dependent correction of the solvent relative permittivity in the Pitzer-Debye-Hückel term was successfully applied to the representation of vapor-liquid equilibria of methanol-water and ethanol-water mixtures with several salts. Results obtained on isothermal and isobaric VLE are very satisfactory, even if slightly less agreement was obtained for $\mathrm{NaBr}$ in methanol and $\mathrm{LiCl}$ in ethanol for high molalities.

\section{List of symbols}

$\begin{array}{ll}a & \text { attractive term } \\ b & \text { covolume } \\ e & \text { charge of one electron } \\ g & \text { molar Gibbs free energy } \\ k & \text { Boltzmann's constant. } \\ m & \text { molality (with respect to } \mathrm{H}_{2} \mathrm{O} \text { ) } \\ m_{s} & \text { molality (with respect to water+alcohol) } \\ M & \text { molecular weigth } \\ n & \text { mole number }\end{array}$




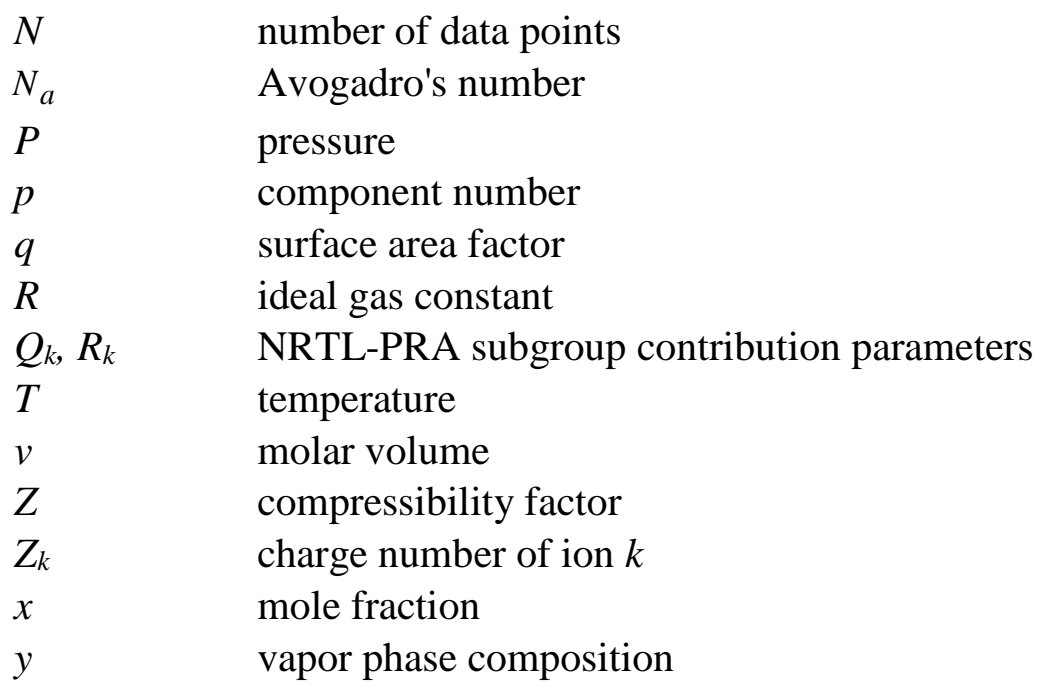

Greek letters

$\begin{array}{ll}\alpha & \text { alpha function } \\ \varepsilon_{r} & \text { relative permittivity } \\ \varepsilon_{0} & \text { vacuum permittivity } \\ \Gamma_{j i} & \text { interaction parameter between molecules } j \text { and } i \\ \Gamma_{L K} & \text { interaction parameter between main groups } K \text { and } L \\ \omega & \text { acentric factor } \\ \theta_{i K} & \text { probability that a contact from molecule } i \text { involves a main group } K \\ v_{i K} & \text { number of main group } K \text { in molecule } i\end{array}$

Subscript

$\begin{array}{ll}\text { diss } & \text { dissociation property } \\ i & \text { pure component property } \\ \text { ion } & \text { ion property } \\ \text { LR } & \text { Long-Range interaction } \\ P, T, y & \text { pressure, temperature, vapor mole fraction } \\ \text { res } & \text { residual property } \\ \text { salt } & \text { salt property } \\ \text { SF } & \text { Salt-Free } \\ \text { SMR } & \text { Short-Middle-Range interaction } \\ \text { tot } & \text { total number of components : SF (solvents) + ions } \\ \text { vap } & \text { vapor }\end{array}$

Superscript

E $\quad$ excess property at constant pressure

\section{APPENDIX A. EoS pure component parameter estimation}

The attractive term $a_{i}$ and the covolume $b_{i}$ in Table 5 are estimated from the critical temperature and pressure, $T_{c i}$ and $P_{c i}$ respectively, by the formulae:

$$
a_{i}=0.45723553 \frac{R^{2} T_{c_{i}}^{2}}{P_{c_{i}}} f\left(T_{r}\right), b_{i}=0.07779607 \frac{R T_{c_{i}}}{P_{c_{i}}}
$$


where $T_{r}$ is the reduced temperature, $T_{r}=T / T_{c_{i}}$, and $f\left(T_{r}\right)$ is the generalized Soave function [84]:

$$
f\left(T_{r}\right)=\left[1+m\left(1-T_{r}^{\gamma}\right)\right]^{2}
$$

For ethanol, we still consider the original Soave function corresponding to $\gamma=0.5$ [85] with the parameter $m$ correlated to the acentric factor $\omega(\omega=0.6350)$ through the equation:

$$
m=0.379642+1.48503 \omega-0.164423 \omega^{2}+0.016666 \omega^{3}
$$

On the other hand, for water and methanol, $\gamma$ and $m$ parameters are fixed to the values previously proposed in [84] to improve vapor pressure representations:

$$
\begin{array}{ll}
\gamma=0.65, m=0.6864 & \text { for water } \\
\gamma=0.9, m=0.6969 & \text { for methanol }
\end{array}
$$

\section{APPENDIX B. Group contribution parameter estimation}

In the NRTL-PRA EoS, binary interaction parameters $\Gamma_{j i}$ in the expression of $g_{S M R}^{E}$ (Table 5) are estimated with the group contribution method developed in [39]:

$$
\Gamma_{j i}=\sum_{K} \theta_{i K} \sum_{L}\left(\theta_{j L}-\theta_{i L}\right) \Gamma_{L K}, \Gamma_{K K}=0
$$

where $\theta_{i K}$ is the probability that a contact from a molecule $i$ involves a main group $K$ :

$$
\theta_{i K}=\sum_{k} v_{i k(K)} \frac{Q_{k}}{q_{i}}, q_{i}=\sum_{k} v_{i k(K)} Q_{k}
$$

with $v_{i k(K)}$ the number of subgroup $k$ belonging to the main group $K$ in a molecule $i$ and $q_{i}$ its corresponding surface area factor; the values of group parameters $Q_{k}$ are reported in Table 6 .

The dependence of group contribution parameters $\Gamma_{L K}$ with respect to temperature is given, in Tables 7a, 7b and 7c, by:

$$
\Gamma_{L K}=\Gamma_{L K}^{(0)}+\Gamma_{L K}^{(1)}\left(\frac{T_{0}}{T}-1\right)+\Gamma_{L K}^{(2)}\left(\frac{T}{T_{0}}-1\right)
$$

where $T_{0}=298.15 \mathrm{~K}$ and $\Gamma_{L K}^{(2)}=0$, except for interactions between the group $\mathrm{H}_{2} \mathrm{O}$ and groups $\mathrm{OH}$ of alcohols (Table 7c).

\section{References}

[1] M. A. A. Fakhree, D. R. Delgado, F. Martínez, A. Jouyban, AAPS Pharm. Sci. Tech. 11 (2010) 1726-1729.

[2] J. A. McNaney, F. M. Zimmerman, H. K. Zimmerman, Monatsh. Chem. 114 (1983) 1321-1335.

[3] J. E. Ricci, T. W. Davis, J. Am. Chem. Soc. 62 (1940) 407-413.

[4] X. Zhang, Q. Yin, P. Cui, Z. Liu, J. Gong, Ind. Eng. Chem. Res. 51 (2012) 6933-6938.

[5] J. Li, H. M. Polka, J. Gmehling, Fluid Phase Equilib. 94 (1994) 89-114. 
[6] W. Yan, M. Tophoff, C. Rose, J. Gmehling, Fluid Phase Equilib. 162 (1999) 97-119.

[7] A. Mohs, J. Gmehling, Fluid Phase Equilib. 337 (2013) 311-322.

[8] C. C. Chen, H. I. Britt, J. F. Boston, L. B. Evans, AIChE J. 28 (1982) 588-596.

[9] B. Mock, C. C. Chen, AIChE J. 32 (1986) 1655-1664.

[10] J. Li,, M. Topphoff, K. Fisher, J. Gmehling, Ind. Eng. Chem. Res. 40 (2001) 3703-3710.

[11] E. Collinet, J. Gmehling, Fluid Phase Equilib. 246 (2006) 111-118.

[12] G. M. Kontogeorgis, B. Maribo-Mogensen, K. Thomsen, Fluid Phase Equilib. 462 (2018) 130152.

[13] A. Galindo, A. Gil-Villegas, G. Jackson, A.N. Burgess, J. Phys. Chem. B 103 (1999) 1027210281.

[14] J. M. A. Schreckenberg, S. Dufal, A. J. Haslam, C. S. Adjiman, G. Jackson, A. Galindo, Mol. Phys. 112 (2014) 2339-2364.

[15] D. K. Eriksen, G. Lazarou, A. Galindo, G. Jackson, C. S. Adjiman, A. J. Haslam, Mol. Phys. 114 (2016) 2724-2749.

[16] E. Neau, C. Nicolas, L. Avaullée, Fluid Phase Equilib. 458 (2018) 194-210.

[17] P. Debye, E. Hückel, Phys. Z. 24 (1923) 179-207.

[18] L. Blum, Mol. Phys., 30 (1975) 1529-1535.

[19] L. Blum, In Theoretical Chemistry: Advances and Perspectives, Academic Press Inc, 1980; Vol. 5, pp $1-65$, ISBN: 9780126819052.

[20] P. Wang, A. Anderko, Fluid Phase Equilib. 186 (2001) 103-122.

[21] B. Maribo-Mogensen, G. M. Kontogeorgis, K. Thomson, J. Phys. Chem. B 117 (2013) 3389-3397.

[22] J. N. Wilson, Chem. Rev. 25 (1939) 377-406.

[23] J. G. Kirkwood, J. Chem. Phys. 7 (1939) 911-919.

[24] W.M. Haynes, CRC Handbook of Chemistry and Physics, 95th edition, CRC Press, 2014.

[25] Y. X. Zuo, W. Fürst, Fluid Phase Equilib. 138 (1997) 87-104.

[26] D. P. Fernández, A. R. H. Goodwin, E. W. Lemmon, J. M. H. Levelt Sengers, R. C. Williams, J. Phys. Chem. Ref. Data 26 (1997) 1125-1166.

[27] S. P. Tan, H. Adidharma, M. Radosz, Ind. Eng. Chem. Res. 44 (2005) 4442-4452.

[28] A. Zuber, L. Cardozo-Filho, V. F. Cabral, R. F. Checoni, M. Castier, Fluid Phase Equilib. 376 (2014) 116-123.

[29] A. Zuber, R. F. Checoni, M. Castier, Braz. J. Chem. Eng. 32 (2015) 637-646.

[30] L. Chunxi, W. Fürst, Chem. Eng. Sci. 55 (2000) 2975-2988.

[31] M. Uematsu, E.U. Franck, J. Phys. Chem. Ref. Data 9 (1980) 1291-1306.

[32] D. I. Karpov, D. A. Medvedev, J. Phys. Conf. Ser. 754 (2016) 102004.

[33] V. Vadillo, J. Sánchez-Oneto, J. R. Portela, E. J. Martínez de la Ossa, Ind. Eng. Chem. Res. 52 (2013) 7617-7629.

[34] K. S. Pitzer, J. Am. Chem. Soc. 102 (1980) 2902-2906. 
[35] E. Neau, I. Raspo, Unpublished results.

[36] E. Neau, I. Raspo, J. Escandell, Fluid Phase Equilib. 427 (2016) 126-142.

[37] D.Y. Peng, D.B. Robinson, Ind. Chem. Fundam. 15 (1976) 59-64.

[38] E. Neau, J. Escandell, C. Nicolas, Ind. Eng. Chem. Res. 49 (2010) 7580-7588.

[39] E. Neau, J. Escandell, C. Nicolas, Ind. Eng. Chem. Res. 49 (2010) 7589-7596.

[40] H.K Hansen, P. Rasmussen, A. Fredenslund, M. Schiller, J. Gmehling, Ind. Eng. Chem. Res., 30 (1991) 2352-2355.

[41] G. S. Anderson, R. C. Miller, J. Chem. Eng. Data 45 (2000) 549-554.

[42] J. Hamelin, J. B. Mehl, M. R. Moldover, Int. J. Thermophys. 19 (1998) 1359-1380.

[43] C. H. Collie, J. B. Hasted, D. M. Ritson, Proc. Phys. Soc. 60 (1948) 145-160.

[44] D. P. Fernández, A. R. H. Goodwin, J. M. H. Levelt Sengers, Int. J. Thermophys. 16 (1995) 929955.

[45] K. R. Srinivasan, R. L. Kay, J. Chem. Phys. 60 (1974) 3645-3649.

[46] E. Volf, Ph. D. Thesis, University of Paris XI N ${ }^{\circ} 2392,1981$.

[47] D. Bertolini, M. Cassettari, G. Salvetti, J. Chem Phys. 76 (1982) 3285-3290.

[48] I. M. Hodge, C. A. Angell, J. Chem Phys. 68 (1978) 1363-1368.

[49] J. B. Hasted, M. Shahidi, Nature 262 (1976) 777-778.

[50] E. Wasserman, B. Wood, J. Brodholt, Geochim. Cosmochim. Acta 59 (1995) 1-6.

[51] D. P. Fernández, Y. Mulev, A. R. H. Goodwin, J. M. H. Levelt Sengers, J. Phys. Chem. Ref. Data 24 (1995) 33-69.

[52] E. W. Rusche, W. B. Good, J. Chem. Phys. 45 (1966) 4667-4668.

[53] R. Abegg, Ann. Phys. (Weid) 60 (1897) 54-60.

[54] R. M. Shirke, A. Chaudhari, N. M. More, P. B. Patil, J. Chem. Eng. Data 45 (2000) 917-919.

[55] D. W. Davidson, Can. J. Chem. 35 (1957) 458-473.

[56] B. Lone, V. Madhurima, J. Mol. Model. 17 (2011) 709-719.

[57] T. Teutenberg, S. Wiese P. Wagner, J. Gmehling, J. Chromatogr. A 1216 (2009) 8480-8487.

[58] A. Chmielewska, M. Zurada, K. Klimaszewski, A. Bald, J. Chem. Eng. Data 54 (2009) 801-806.

[59] M. T. Khimenko, V. V. Aleksandrov, N. N. Gritsenko, Zh. Fiz. Khim. 47 (1973) 2914-2915

[60] S. M. Pereira, T. P. Iglesias, J. L. Legido, M. A. Rivas, J. N. Real, J. Chem. Thermodyn. 33 (2001) 433-440.

[61] V. A. Granzhan, O. G. Kirillova, Zh. Prikl. Khim. 43 (1970) 1875-1877.

[62] M. Mohsen-Nia, H. Amiri, B. Jazi, J. Solution Chem. 39 (2010) 701-708.

[63] E. U. Franck, R. Deul, Faraday Discuss. Chem. Soc. 66 (1978) 191-198.

[64] M. Nicolas, M. Malineau, R. Reich, Phys. Chem. Liq. 10 (1980) 11-22.

[65] A. P. Krasnoperova, A. A. Asheko, J. Struct. Chem. 18 (1978) 760-762.

[66] M. Claudius, Diploma Work, Merseburg, 1975. 
[67] F. Travers, P. Douzou, J. Phys. Chem. 74 (1970) 2243-2244.

[68] G. H. Barbenza, J. Chim. Phys. Phys. Chim. Biol. 65 (1968) 906.

[69] W. Dannhauser, L. W. Bahe, J. Chem. Phys. 40 (1964) 3058-3065.

[70] D. J. Denney, R. H. Cole, J. Chem Phys. 23 (1955) 1767-1771.

[71] E. Fischer, Z. Phys. 127 (1950) 49.

[72] F. R. Goss, J. Chem. Soc. London (1940) 888-894.

[73] A. Chaudhari, N. M. More, S. C. Mehrotra, Bull. Korean Chem. Soc. BKCS 22 (2001) 357-361.

[74] A. P. Gregory, R. N. Clarke, Meas. Sci. Technol. 16 (2005) 1506-1516.

[75] M. C. Mateos, P. Perez, F. M. Royo, M. Gracia, C. Gutierrez Losa, Rev. Acad. Cienc. Exactas Fis. Quim. Nat. Zaragoza 41 (1986) 73-82.

[76] M. T. Rätzsch, C. Wohlfarth, M. Claudius, J. Prakt. Chem. 319 (1977) 353-361.

[77] B. M. Fridman, Zh. Fiz. Chim. 49 (1975) 2425.

[78] A. Watanabe, S. Sugiyama, Rep. Gov. Ind. Res. Inst. Nagoya 22 (1973) 67.

[79] P. S. Krishna Mohana, D. Premaswarup, Indian J. Pure Appl. Phys. 8 (1970) 316.

[80] M. W. Sagal, J. Chem. Phys. 36 (1962) 2437-2442.

[81] L. Andrusov, Z. Phys. Chem. Leipzig 215 (1960) 372.

[82] F. X. Hassion, R. H. Cole, J. Chem. Phys. 23 (1955) 1756-1761.

[83] C. P. Smyth, W. N. Stoops, J. Amer. Chem. Soc. 51 (1929) 3312-3329.

[84] E. Neau, I. Raspo, J. Escandell, C. Nicolas, O. Hernández-Garduza, Fluid Phase Equilib. 276 (2009) 156-164.

[85] G. Soave, Chem. Eng. Sci. 27 (1972) 1197-1340.

[86] B. Maribo-Mogensen, G. M. Kontogeorgis, K. Thomson, Ind. Eng. Chem. Res. 51 (2012) 53535363.

[87] N. Gavish, K. Promislow, Phys. Rev. E. 94 (2016) 012611.

[88] J. V. Walther, J. Schott, Nature 332 (1988) 635-638.

[89] M. L. Michelsen, J. M. Mollerup, Thermodynamic Models: Fundamentals \& Computational Aspects, Tie-Line Publications: Holte, Denmark, 2007.

[90] I. Mokbel, S. Ye, J. Jose, P. Xans, J. Chim. Phys. Phys. Chim. Biol. 94 (1997) 122-137.

[91] N. Hubert, Y. Gabes, J. B. Bourdet, L. Schuffenecker, J. Chem. Eng. Data 40 (1995) 891-894.

[92] B. Li, Y. Luo, Z. Zhu, Huagong Xuebao 37 (1986) 51-58.

[93] G. Tammann, Z. Phys. Chem. Leipzig 2 (1888) 42-47.

[94] E. R. Gardner, P. J. Jones, H. J. De Nordwall, Trans. Faraday Soc. 59 (1963) 1994-2000.

[95] C. T. Liu, W. T. Lindsay, Res. Develop. Progr. Rep. 722 (1971) 124.

[96] C. T. Liu, W. T. Lindsay, J. Solution Chem. 1 (1972) 45-69.

[97] I. K. Khaibullin, N. M. Borisov, High Temp. 4 (1966) 489-494.

[98] C. T. Liu, W. T. Lindsay, J. Phys. Chem. 74 (1970) 341-346. 
[99] S. A. Wood, D. A. Crerar, S. L. Brantley, M. Borcsik, Am. J. Sci. 284 (1984) 668-705.

[100] V. P. Mashovets, V. I. Zarembo, M. K. Fedorov, Zh. Prikl. Khim. 46 (1973) 650-652.

[101] C. J. Parisod, E. J. Plattner, J. Chem. Eng. Data 26 (1981) 16-20.

[102] V. P. Mashovets, V. I. Zarembo, M. K. Fedorov, J. Appl. Chem. USSR 46 (1973) 684-686.

[103] K. R. Patil, A. D. Tripathi, G. Pathak, J. Chem. Eng. Data 36 (1991) 225-230.

[104] K. R. Patil, F. Olive, A. Coronas, J. Chem. Eng. Japan 27 (1994) 680-681.

[105] I. K. Khaibullin, N. M. Borisov, High Temp. 4 (1966) 489-494.

[106] R. Crovetto, S. N. Lvov, R. H. Wood, J. Chem. Thermodyn. 25 (1993) 127-138.

[107] E. F. Johnson, M. C. Molstad, J. Phys. Chem. 55 (1951) 257-281.

[108] K. R. Patil, A. D. Tripathi, G. Pathak, S. S. Katti, J. Chem. Eng. Data 35 (1990) 166-168.

[109] S. K. Chaudhari, K. R. Patil, Phys. Chem. Liq. 40 (2002) 317-325.

[110] A. Apelblat, J. Chem. Thermodyn. 25 (1993) 63-71.

[111] G. Jakli, W. A. Van Hook, J. Chem. Eng. Data 17 (1972) 348-355.

[112] G. Feuerecker. J. Scharfe, I. Greiter. C. Frank, G. Alefeld, Proceedings of International Absorption Heat Pump Conference, AES-Vol. 31 (1994). p. 493.

[113] S. Iyoki, T. Uemura, Int. J. Refrig. 12 (1989) 278-282.

[114] J. L. Y. Lenard, S. M. Jeter, A. S. Teja, ASHRAE Trans. 98 (1992) 167-172.

[115] Z. Lan, X. Ma, Z. Hao, R. Jiang, Int. J. Refrig. 76 (2017) 73-83.

[116] H. Hsu, Y. Wu, L. Lee, J. Chem. Eng. Data 48 (2003) 514-518.

[117] J. M. ShiA, H. C. Teng, Fluid Phase Equilib. 124(1996) 235-249.

[118] R. A. Robinson, V. E. Bower, J. Res. NBS A (Phys and Chem) 69 (1965) 365-367.

[119] S. O. Yang, C. S. Lee, J. Chem. Eng. Data 43 (1998) 558-561.

[120] M. Joedecke, A. Perez-Salado Kamps, G. Maurer, J. Chem. Eng. Data 50(1) (2005) 138-141.

[121] J. Yao, H. Li, S. Han, Fluid Phase Equilib. 162 (1999) 253-260.

[122] J. F. Morrison, J. C. Baker, H. C. Meredith, K. E. Newman, T. D. Walter, J. D. Massie, R. L. Perry, P. T. Cummings, J. Chem. Eng. Data, 35 (1990) 395-404.

[123] A. I. Johnson, W. F. Furter, Can. J. Chem. Eng. 38 (1960) 78-87.

[124] I. Barthel, R. Neueder, G. Lauermann, J. Sol. Chem. 14 (1985) 621-633.

[125] J.H. Kiepe, Shaker, Aachen (2004) 1-172.

[126] H. Nishi, N. Kanai, Wakayama Kogyo Koto Senmon Gakko Kenkyu Kiyo 20 (1985) 47-50.

[127] H. Nishi, N. Kanai, Wakayama Kogyo Koto Senmon Gakko Kenkyu Kiyo 25 (1990) 71-74.

[128] J. E. Boone, R. W. Rousseau, E. M. Schoenborn, Adv. Chem. Ser. 155 (1976) 36-52.

[129] S. Ohe, Vapor-liquid equilibrium data - salt effect, elsevier, 1991.

[130] R. Yang, J. Demirgian, J. F. Solsky, E. J. Kikta, J. A. Marinsky, J. Phys. Chem. 83(21) 1979 2752-2761.

[131] T. Meyer, H. M. Polka, J. Gmehling, J. Chem. Eng. Data 36(3) 1991 340-342. 
[132] L. L. Dobroserdov, V. P. Il'yina, Tr. Leningradskogo Tekhnologicheskogo Instituta Pishchevoi Promyshlennosti, 14 (1958) 143-146.

[133] A. Rius Miro, J. L. Otero de la Gandara, J. R. A. Gonzalez, An. R. Soc. Esp. Fis. Quim. Ser. B 53 (1957) 171-183.

[134] R. Sun, Huaxue Gongcheng 23(1) 13-17.

[135] J.T. Safarov, Fluid Phase Equilib. 243 (2006) 38-44. 


\section{LIST OF TABLES}

Table 1. Database for relative permittivity: number of data points $(N)$, interval of experimental temperatures (T-range in Kelvin) and references (Ref).

Table 2. New correlation: fitted parameter values of Eq. (1) for relative permittivity.

Table 3. Parameter values of the literature correlations for relative permittivity, together with their temperature range of validity. NR: Eq. (1) with parameters given in [16], CRC: Eq. (2) with parameters of [24], ZZC: Eq. (3) with parameters of [25, 30] for water and ethanol and [29] for methanol.

Table 4. Mean percent relative deviations on relative permittivity obtained with various correlations for data described in Table 1. Interval of experimental temperatures (T-range in Kelvin, with, in parenthesis, according to Table 3, the correlation concerned by this range of validity), number of data points $(N)$ and name of the correlation: NR: Eq. (1) with parameters given in [16], CRC: Eq. (2) with parameters of [24], ZZC: Eq. (3) with parameters of [25, 30] for water and ethanol and [29] for methanol.

Table 5. The NRTL-PRA EoS [16].

Table 6. NRTL-PRA groups $K$ and subgroups $k$ : surface area $Q_{k}[R e f$.].

Table 7a. Values (in J/mol) of the NRTL-PRA group interaction parameters $\Gamma_{L K}^{(0)}$ (oll = methanol, ol2 $=$ ethanol). This work: parameters between alcohol groups $(\mathbf{O H}($ oll $), \mathbf{O H}($ ol2 $))$ and ions. Other parameters are taken from [16] and [36].

Table 7b. Values (in J/mol) of the NRTL-PRA group interaction parameters $\Gamma_{L K}^{(1)}$ (oll = methanol, ol2 $=$ ethanol). This work: parameters between alcohol groups $(\mathbf{O H}($ oll $), \mathbf{O H}($ ol2 $))$ and ions. Other parameters are taken from [16] and [36].

Table 7c. Values (in $\mathrm{J} / \mathrm{mol})$ of the non-zero NRTL-PRA group interaction parameters $\Gamma_{L K}^{(2)}(o l 1=$ methanol, ol2 = ethanol) [16].

Table 8. Literature data of vapor pressure $P_{\text {vap }}$ of aqueous electrolytes: number of data points $(N)$, interval of experimental temperatures (T-range in Kelvin), maximum molality $\left(m_{\max }\right)$, interval of experimental pressures ( $P$-range in bar) and references $($ Ref).

Table 9. Values of ion-specific parameter $\alpha_{k}$ in Eq. (6).

Table 10. Mean percent relative deviation $\Delta P_{\text {vap }} / P_{\text {vap }} \%$ on vapor pressure of aqueous electrolyte solutions with maximum molality $m_{\max }<10$. Prediction with the NRTL-PRA EoS and the new correlation for the relative permittivity of water Without (Table 5) or With (Eq. (5)) the correction factor E. Literature data: number of data points $(N)$ and maximum pressure $\left(P_{\max }\right.$ in bar).

Table 11. Mean percent relative deviation $\Delta P_{\text {vap }} / P_{\text {vap }} \%$ on vapor pressure of aqueous electrolyte solutions with two electrolytes. Prediction with the NRTL-PRA EoS and the new correlation for the relative permittivity of water Without (Table 5) or With (Eq. (5)) the correction factor E. Literature data: number of data points $(N)$, maximum molality between salt 1 or salt $2\left(m_{\max }\right)$ and maximum pressure $\left(P_{\max }\right.$ in bar). 
Table 12. Mean percent relative deviation $\Delta P_{\text {vap }} / P_{\text {vap }} \%$ on vapor pressure of aqueous electrolyte solutions with maximum molality $m_{\max }>10$. Prediction with the NRTL-PRA EoS and the new correlation for the relative permittivity of water Without (Table 5) or With (Eq. (5)) the correction factor $E$. Literature data: number of data points $(N)$ and maximum pressure $\left(P_{\max }\right.$ in bar).

Table 13. Mean percent relative deviations $\triangle P / P \%$ and $\triangle T / T \%$ on isothermal VLE and isobaric VLE, respectively, together with $\Delta y / y \%$ on the vapor phase, obtained with the NRTL-PRA EoS for alcoholwater mixtures with several salts. Literature data: intervals of experimental temperatures (T-range), pressures (P-range), amount of salt introduced in the solvent mixture ( $m$-range), type* of measurements and references (Ref.). Modeling: isothermal data, with number of pressures $\left(N_{P}\right)$ and deviations $(\triangle P / P \%)$; isobaric data, with number of temperatures $\left(N_{T}\right)$ and deviations $(\triangle T / T \%)$; vapor phase composition data, with number of points $\left(N_{y}\right)$ and deviations $(\Delta y / y \%)$.

type* : salt molality $(m)$, mole fraction of salt $(x)$.

Table 14. Prediction of isothermal VLE provided by the NRTL-PRA EoS for methanol-water mixture with two salts at $298.15 \mathrm{~K}$. Literature data: intervals of experimental pressures $(P$-range), amount of salt introduced in the solvent mixture ( $m$-range), type of measurements (salt molality $m$ ), references (Ref.), number of pressures $\left(N_{P}\right)$ and deviations $(\triangle P / P)$; vapor phase composition data, with number of points $\left(N_{y}\right)$ and deviations $(\Delta y / y \%)$ 


\section{LIST OF FIGURES}

Fig. 1. Relative permittivity for (a) water, (b) methanol, (c) ethanol. Variation of $\varepsilon_{r}$ with respect to temperature obtained with: the new correlation (purple solid line), NR correlation (pink dashed line), CRC correlation (orange dash-dotted line) and ZZC correlation (blue dotted line). Circles correspond to experimental data of Table 1 and the two vertical dotted lines delimitate the temperature range of the CRC Handbook of Chemistry and Physics [24].

Fig. 2. Relative permittivity for (a) water, (b) methanol, (c) ethanol. Variation of $\varepsilon_{r}$ with respect to temperature obtained with the new correlation (purple solid line) and with fitted parameters for Eq. (2) (orange dash-dotted line) and Eq. (3) (blue dotted line). Circles correspond to experimental data of Table 1 and the two vertical dotted lines delimitate the temperature range of the CRC Handbook of Chemistry and Physics [24].

Fig. 3. Vapor pressure of water with $\mathrm{NaCl}$ for various molalities $m$ : $m=1, \square m=3, \Delta m=6$. Prediction with the NRTL-PRA EoS for $m=0$ (solid blue line), $m=1$ (dashed pink line), $m=3$ (dashdotted green line) and $m=6$ (dotted orange line) and, for $\varepsilon_{r}^{*}$ in $g_{L R}^{E}$ (Table 5): the NR correlation (a, b) and the new correlation (c, d).

Fig. 4. Vapor pressure of water with $\mathrm{NaCl}$ for various molalities $m: \bullet m=1, \square m=3, \Delta m=6$. Calculation with the NRTL-PRA EoS by fitting binary interaction parameters $\Gamma_{\mathrm{H}_{2} \mathrm{O} / \mathrm{Na}^{+}}$and $\Gamma_{\mathrm{H}_{2} \mathrm{O} / \mathrm{Cl}^{-}}$ for $m=0$ (solid blue line), $m=1$ (dashed pink line), $m=3$ (dash-dotted green line) and $m=6$ (dotted orange line) and with the new correlation for $\varepsilon_{r}^{*}$ in $g_{L R}^{E}:(\mathrm{a}, \mathrm{b})$ Parameters fitted on data for $T$ up to $450 \mathrm{~K} \quad\left(\Gamma_{\mathrm{H}_{2} \mathrm{O} / \mathrm{Na}^{+}}^{(0)}=-3543.75, \quad \Gamma_{\mathrm{H}_{2} \mathrm{O} / \mathrm{Na}^{+}}^{(1)}=4050.00, \quad \Gamma_{\mathrm{H}_{2} \mathrm{O} / \mathrm{Cl}^{-}}^{(0)}=-3041.30, \quad \Gamma_{\mathrm{H}_{2} \mathrm{O} / \mathrm{Cl}^{-}}^{(1)}=1013.77\right.$, $\left.\Gamma_{\mathrm{H}_{2} \mathrm{O} / \mathrm{Na}^{+}}^{(2)}=\Gamma_{\mathrm{H}_{2} \mathrm{O} / \mathrm{Cl}^{-}}^{(2)}=0\right)$; (c, d) Parameters fitted on data for $\mathrm{T}>450 \mathrm{~K}\left(\Gamma_{\mathrm{H}_{2} \mathrm{O} / \mathrm{Na}^{+}}^{(0)}=1628.80, \Gamma_{\mathrm{H}_{2} \mathrm{O} / \mathrm{Na}^{+}}^{(1)}=\right.$ -2166.91, $\left.\Gamma_{\mathrm{H}_{2} \mathrm{O} / \mathrm{Cl}^{-}}^{(0)}=1929.33, \Gamma_{\mathrm{H}_{2} \mathrm{O} / \mathrm{Cl}^{-}}^{(1)}=845.94, \Gamma_{\mathrm{H}_{2} \mathrm{O} / \mathrm{Na}^{+}}^{(2)}=\Gamma_{\mathrm{H}_{2} \mathrm{O} / \mathrm{Cl}}^{(2)}=0\right)$.

Fig. 5. Vapor pressure of water with $\mathrm{NaCl}$ for various molalities $m$ : $m=1, \square m=3, \Delta m=6$. Prediction with the NRTL-PRA EoS for $m=0$ (solid blue line), $m=1$ (dashed pink line), $m=3$ (dashdotted green line) and $m=6$ (dotted orange line) and, in $g_{L R}^{E}, \varepsilon_{r}^{*}$ calculated with Eq.(5) and the new correlation.

Fig. 6. Vapor pressure of water with $\mathrm{KBr}$ for various molalities $m(\diamond m=2, \square m=4, \Delta m=6)$. Prediction with the NRTL-PRA EoS for $m=0$ (solid blue line), $m=2$ (dashed pink line), $m=3$ (dashdotted green line) and $m=6$ (dotted orange line) and, in $g_{L R}^{E}, \varepsilon_{r}^{*}$ calculated with Eq.(5) and the new correlation.

Fig. 7. Vapor pressure of water with $\mathrm{NaCl}^{1}$ and $\mathrm{KBr}^{2}$ for $m_{1}=m_{2}=1(\diamond)$ and $m_{1}=m_{2}=2(\square)$. Prediction with the NRTL-PRA EoS for $m_{1}=m_{2}=0$ (solid blue line), $m_{1}=m_{2}=1$ (dashed pink line) and $m_{1}=m_{2}=2$ (dash-dotted green line) and, in $g_{L R}^{E}, \varepsilon_{r}^{*}$ calculated with Eq.(5) and the new correlation.

Fig. 8. VLE of methanol ${ }^{(1)}$-water $^{(2)}$ with: (a) $\mathrm{NaCl}$ at $T=396 \mathrm{~K}$ for $m_{s}=0(\square), m_{s}=2.76(\Delta), m_{s}=4.84(\odot)$, (b) $\mathrm{KCl}$ at $P=1.01$ bar for $m=0.5(\bullet), m=1(\triangle), m=2(\odot)$, (c) $\mathrm{LiCl}$ at $P=1.01$ bar for $m=1(\square, \square), m=2($ 
$\Delta, \Delta), m=4(\odot, \bullet),(\mathrm{d}) \mathrm{NaBr}$ at $T=313 \mathrm{~K}$ for $m_{s}=1(\bullet), m_{s}=2(\Delta), m_{s}=4(\odot)$. Calculation with the NRTLPRA EoS (一).

Fig. 9. VLE of ethanol ${ }^{(1)}$ - water $^{(2)}$ with: (a) $\mathrm{NaCl}$ at $P=1.01$ bar for $x_{\mathrm{NaCl}}=0$ (๑), $x_{\mathrm{NaCl}}=0.01(\odot), x_{\mathrm{NaCl}}=0.03$ $(\diamond, \bullet), x_{N a C l}=0.05(\triangle),(\mathrm{b}) \mathrm{KCl}$ at $T=298 \mathrm{~K}$ for $m_{s}=0(\bullet), m_{s}=0.3(\Delta), m_{s}=0.5(\odot), m_{s}=1(\diamond),(\mathrm{c}) \mathrm{LiCl}$ at $T=298 \mathrm{~K}$ for $m_{s}=0(\square), m_{s}=0.5(\triangle), m_{s}=1(\odot)$. Calculation with the NRTL-PRA EoS ( $)$. 


\section{Table 1}

Database for relative permittivity: number of data points $(N)$, interval of experimental temperatures $(T$ range in Kelvin) and references (Ref).

\begin{tabular}{lccl}
\hline Compound & $N$ & T-range $(K)$ & References \\
\hline Water & 192 & $193.15-823.15$ & {$[31],[41]-[53]$} \\
Methanol & 158 & $163.20-525.00$ & {$[54]-[71]$} \\
Ethanol & 109 & $130.60-513.20$ & {$[54],[59],[62],[69],[71]-[83]$} \\
\hline
\end{tabular}

\section{Table 2}

New correlation: fitted parameter values of Eq. (1) for relative permittivity.

\begin{tabular}{lccccc}
\hline Compound & $A_{0}$ & $A_{1}$ & $A_{2}$ & $A_{4}$ & $A_{5}$ \\
\hline Water & -1664.4988 & -0.884533 & 0.0003635 & 64839.1736 & 308.3394 \\
Methanol & -1750.3069 & -0.99026 & 0.0004666 & 51360.2652 & 327.3124 \\
Ethanol & -1522.2782 & -1.00508 & 0.0005211 & 38733.9481 & 293.1133 \\
\hline
\end{tabular}




\section{Table 3}

Parameter values of the literature correlations for relative permittivity, together with their temperature range of validity. NR: Eq. (1) with parameters given in [16], CRC: Eq. (2) with parameters of [24], ZZC: Eq. (3) with parameters of [25, 30] for water and ethanol and [29] for methanol.

\begin{tabular}{|c|c|c|c|c|c|c|c|}
\hline Correlation & $A_{0}$ & $A_{l}$ & $A_{2} \times 10^{3}$ & $A_{3} \times 10^{6}$ & $A_{4}$ & $A_{5}$ & $T$-range $(K)$ \\
\hline \multicolumn{8}{|c|}{ Water } \\
\hline NR & 5154.4005 & 2.44666 & -0.9500 & - & -83627.2140 & -954.9807 & - \\
\hline $\mathrm{CRC}$ & 249.2100 & -0.796069 & 0.72997 & 0.00 & - & - & $273-372$ \\
\hline $\mathrm{ZZC}$ & -19.2905 & -0.019678 & 0.13189 & -0.31144 & 29814.5 & - & $288-403$ \\
\hline \multicolumn{8}{|c|}{ Methanol } \\
\hline NR & 2808.6924 & 1.49172 & -0.6300 & - & -42566.6494 & -530.4343 & - \\
\hline $\mathrm{CRC}$ & 193.4100 & -0.92211 & 1.2839 & 0.00 & - & - & $177-293$ \\
\hline $\mathrm{ZZC}$ & 104.6200 & 0.090108 & -2.5998 & 4.8503 & 1000.00 & - & $176-318$ \\
\hline \multicolumn{8}{|c|}{ Ethanol } \\
\hline NR & -288.2401 & -0.06543 & 0.01200 & - & 18909.8285 & 47.0709 & - \\
\hline $\mathrm{CRC}$ & 151.4500 & -0.87020 & 1.9570 & -1.5512 & - & - & $163-523$ \\
\hline $\mathrm{ZZC}$ & 175.7200 & -0.35350 & -2.0285 & 5.0644 & -3.0699 & - & $288-328$ \\
\hline
\end{tabular}




\section{Table 4}

Mean percent relative deviations on relative permittivity obtained with various correlations for data described in Table 1. Interval of experimental temperatures (T-range in Kelvin, with, in parenthesis, according to Table 3, the correlation concerned by this range of validity), number of data points $(N)$ and name of the correlation: NR: Eq. (1) with parameters given in [16], CRC: Eq. (2) with parameters of [24], ZZC: Eq. (3) with parameters of [25, 30] for water and ethanol and [29] for methanol.

\begin{tabular}{lccccc}
\hline T-range $(K)$ & $N$ & $C R C$ & ZZC & NR & new correlation \\
\hline & & \multicolumn{5}{c}{ Water } \\
\hline $273-372(C R C)$ & 93 & 0.16 & 0.17 & 0.83 & 0.20 \\
$288-403(Z Z C)$ & 86 & 0.22 & 0.24 & 0.94 & 0.19 \\
$404-823$ & 52 & 364 & 326 & 113 & 5.69 \\
\hline & & & Methanol & \\
\hline $177-293(C R C)$ & 59 & 1.33 & 1.68 & 1.95 & 1.68 \\
$176-318(Z Z C)$ & 109 & 1.90 & 2.10 & 2.25 & 1.91 \\
$319-525$ & 48 & 169 & 346 & 30.81 & 3.16 \\
\hline & & & Ethanol & \\
\hline $288-328(Z Z C)$ & 53 & 3.47 & 2.21 & 3.81 & 1.26 \\
$163-513(C R C)$ & 104 & 24.88 & 275 & 25.59 & 1.59 \\
\hline
\end{tabular}




\section{Table 5}

The NRTL-PRA EoS [16].

\section{- Compressibility factor :}

$$
Z=\frac{P v}{R T}=\frac{1}{1-\eta}-\frac{\alpha \eta}{1+2 \eta-\eta^{2}}
$$

with : $\quad \eta=\frac{b}{v} \quad, \quad b=\sum_{i=1}^{p_{S F}} x_{S F_{i}} b_{i}$

and : $\quad \alpha=\frac{a}{b R T}=\sum_{i=1}^{p_{S F}} x_{S F_{i}} \frac{a_{i}}{b_{i} R T}-\frac{1}{0.53}\left[\frac{g_{E O S}^{E}}{R T}\right]$

- Excess Gibbs energy for electrolyte mixtures:

$$
g_{E o S}^{E}=g_{S M R}^{E}+g_{L R}^{E}+g_{\text {diss }}^{E}
$$

- $g_{S M R}^{E}$ is the Short-Middle-Range excess Gibbs energy:

$$
g_{S M R}^{E}=\sum_{i=1}^{p_{\text {tot }}} x_{i} q_{i} \sum_{j=1}^{p_{\text {tot }}} \frac{x_{j} q_{j} G_{j i}}{\sum_{m} x_{m} q_{m} G_{m i}} \Gamma_{j i}
$$

with : $G_{j i}=\exp \left(\Gamma_{j i} / R T\right)$ and : $q_{i}=q_{i 1}-\left(1-X_{i} / x_{i}\right) / 2 / z$
- $g_{L R}^{E}$ is the Long-Range excess Gibbs energy:

$$
g_{L R}^{E}=-R T\left[\frac{4 A_{x} I_{z}}{\chi} \ln \left(1+\chi \sqrt{I_{z}}\right)\right]
$$

with : $\quad I_{z}=I_{z}\left(x_{i o n}\right)=\frac{1}{2} \sum_{k=1}^{p_{i o n}} x_{i o n_{k}} Z_{k}^{2}$

$$
\chi=\chi\left(x_{S F}\right)=2 / \sqrt{M^{*}}, \quad M^{*}=\sum_{i=1}^{p_{S F}} x_{S F_{i}} M_{i},
$$$$
A_{x}=A_{x}\left(T, x_{S F}\right)=\frac{1}{3}\left(\frac{2 \pi N_{a}}{v *}\right)^{1 / 2}\left(\frac{e^{2}}{4 \pi \varepsilon_{0} \varepsilon_{r}^{*} k T}\right)^{3 / 2}
$$

where : $\varepsilon_{r}^{*}=\sum_{i=1}^{p_{S F}} x_{S F_{i}} b_{i} \varepsilon_{r_{i}} / v * \quad, \quad v^{*}=\sum_{i=1}^{p_{S F}} x_{S F_{i}} b_{i}$

- $g_{\text {diss }}^{E}$ is the dissociation excess Gibbs energy:

$$
g_{\text {diss }}^{E}=\sum_{i=i(\text { asso })}\left(x_{i} X_{i}^{\left(x_{i}=1\right)}-X_{i}\right) E_{i(\text { asso })}^{0}
$$

(for mixtures of Methanol, Ethanol, ... with hydrocarbons)

with : $\quad E_{i(\text { asso })}^{0}=\Delta G_{i}^{0}-(2 / z) E_{i i} \quad(z=10)$

and : $\quad X_{i}=X_{i 1} /\left(1-K_{i} X_{i 1}\right)$

$$
X_{i 1}=\left[\left(1+2 K_{i} x_{i}\right)-\sqrt{1+4 K_{i} x_{i}}\right] /\left[2 K_{i}^{2} x_{i}\right]
$$




\section{Table 6}

NRTL-PRA groups $K$ and subgroups $k$ : surface area $Q_{k}[R e f$. $]$.

\begin{tabular}{cccc}
\hline $\boldsymbol{K}$ & $k$ & $Q_{k}$ & Ref. \\
\hline & $\mathrm{CH}_{3}$ & 0.848 & {$[40]$} \\
& $\mathrm{CH}_{2}$ & 0.540 & {$[40]$} \\
Paraffin $(\mathbf{P A R})$ & $\mathrm{CH}$ & 0.228 & {$[40]$} \\
& $\mathrm{C}$ & 0.000 & {$[40]$} \\
Water $\left(\mathbf{H}_{\mathbf{2}} \mathbf{O}\right)$ & $\mathrm{H}_{2} \mathrm{O}$ & 1.400 & {$[40]$} \\
Alcohol $(\mathbf{O H})$ & $\mathrm{OH}$ & 1.152 & {$[40]$} \\
Sodium cation $\left(\mathbf{N a}^{+}\right)$ & $\mathrm{Na}^{+}$ & 0.360 & {$[16]$} \\
Potassium cation $\left(\mathbf{K}^{+}\right)$ & $\mathrm{K}^{+}$ & 0.500 & {$[16]$} \\
Lithium cation $\left(\mathbf{L i}^{+}\right)$ & $\mathrm{Li}^{+}$ & 0.230 & {$[16]$} \\
Chlorine anion $\left(\mathbf{C l}^{-}\right)$ & $\mathrm{Cl}^{-}$ & 0.720 & {$[16]$} \\
Bromine anion $\left(\mathbf{B r}^{-}\right)$ & $\mathrm{Br}^{-}$ & 0.780 & {$[16]$} \\
\hline
\end{tabular}




\section{Table 7a}

Values (in J/mol) of the NRTL-PRA group interaction parameters $\Gamma_{L K}^{(0)}(o l l=$ methanol, ol $2=$ ethanol). This work: parameters between alcohol groups $(\mathbf{O H}($ oll $), \mathbf{O H}($ ol2 $))$ and ions. Other parameters are taken from [16] and [36].

\begin{tabular}{|c|c|c|c|c|c|c|c|c|c|}
\hline $\mathbf{L} \backslash \mathbf{K}$ & PAR & $\mathrm{H}_{2} \mathrm{O}$ & $\begin{array}{c}\mathbf{O H} \\
(o l 1)\end{array}$ & $\begin{array}{c}\mathbf{O H} \\
(o l 2)\end{array}$ & $\mathbf{N a}^{+}$ & $\mathbf{K}^{+}$ & $\mathbf{L i}^{+}$ & $\mathrm{Cl}^{-}$ & $\mathrm{Br}^{-}$ \\
\hline PAR & 0.00 & 2398.94 & $*$ & 4521.85 & - & - & - & - & - \\
\hline $\mathrm{H}_{2} \mathrm{O}$ & 3245.43 & 0.00 & -1200.31 & 2642.32 & 0.00 & 0.00 & 0.00 & 0.00 & 0.00 \\
\hline $\mathbf{O H}(\mathrm{oll})$ & $*$ & -620.11 & 0.00 & - & 6729.25 & 2215.36 & 3346.72 & 7423.70 & 7962.64 \\
\hline $\mathbf{O H}(o l 2)$ & 2932.98 & -1310.63 & - & 0.00 & 6764.51 & 8969.38 & 9966.39 & 5419.55 & - \\
\hline $\mathrm{Na}^{+}$ & - & 0.00 & 2766.20 & 8192.42 & 0.00 & 0.00 & 0.00 & 0.00 & 0.00 \\
\hline $\mathbf{K}^{+}$ & - & 0.00 & 2071.76 & 6501.73 & 0.00 & 0.00 & 0.00 & 0.00 & 0.00 \\
\hline $\mathbf{L i}^{+}$ & - & 0.00 & 7162.38 & 13825.95 & 0.00 & 0.00 & 0.00 & 0.00 & 0.00 \\
\hline $\mathrm{Cl}^{-}$ & - & 0.00 & 2332.18 & 6869.51 & 0.00 & 0.00 & 0.00 & 0.00 & 0.00 \\
\hline $\mathrm{Br}^{-}$ & - & 0.00 & 3062.71 & - & 0.00 & 0.00 & 0.00 & 0.00 & 0.00 \\
\hline
\end{tabular}

\begin{tabular}{llll}
$* \Gamma^{(0)} \mathrm{OH} / \mathrm{CH} 3=$ & 1535.09 & $* \Gamma^{(0)} \mathrm{CH} 3 / \mathrm{OH}=$ & -235.94 \\
$* \Gamma^{(0)} \mathrm{OH} / \mathrm{CH}=$ & 2185.15 & $* \Gamma^{(0)} \mathrm{CH} 2 / \mathrm{OH}=$ & 2220.91 \\
$* \Gamma^{(0)} \mathrm{OH} / \mathrm{CH}=$ & 9573.00 & $* \Gamma^{(0)} \mathrm{CH} / \mathrm{OH}=$ & 10290.82 \\
\hline
\end{tabular}




\section{Table 7b}

Values (in J/mol) of the NRTL-PRA group interaction parameters $\Gamma_{L K}^{(1)}(o l l=$ methanol, ol $=$ ethanol). This work: parameters between alcohol groups $(\mathbf{O H}($ oll $), \mathbf{O H}($ ol2 $))$ and ions. Other parameters are taken from [16] and [36].

\begin{tabular}{cccccccccc}
\hline $\mathbf{L l K}$ & $\mathbf{P A R}$ & $\mathbf{H}_{\mathbf{2}} \mathbf{O}$ & $\begin{array}{c}\mathbf{O H} \\
(\text { oll })\end{array}$ & $\begin{array}{c}\mathbf{O H} \\
(\text { ol } 2)\end{array}$ & $\mathbf{N a}^{+}$ & $\mathbf{K}^{+}$ & $\mathbf{L i}^{+}$ & $\mathbf{C l}^{-}$ & $\mathbf{B r}^{-}$ \\
\hline $\mathbf{P A R}$ & 0.00 & -3417.62 & $*$ & -5087.56 & - & - & - & - & - \\
$\mathbf{H} \mathbf{O}$ & -294.87 & 0.00 & -1232.08 & -3373.49 & 0.00 & 0.00 & 0.00 & 0.00 & 0.00 \\
$\mathbf{O H}($ oll $)$ & $*$ & -2731.35 & 0.00 & - & -9548.61 & -7625.90 & -868.06 & -6076.39 & -6076.39 \\
$\mathbf{O H}($ ol 2$)$ & -2016.20 & -3903.14 & - & 0.00 & -6496.54 & -21048.62 & -27560.76 & -6496.54 & - \\
$\mathbf{N a}^{+}$ & - & 0.00 & -2885.49 & -30883.64 & 0.00 & 0.00 & 0.00 & 0.00 & 0.00 \\
$\mathbf{K}^{+}$ & - & 0.00 & -16425.91 & -22064.20 & 0.00 & 0.00 & 0.00 & 0.00 & 0.00 \\
$\mathbf{L i}^{+}$ & - & 0.00 & -10567.79 & -51286.41 & 0.00 & 0.00 & 0.00 & 0.00 & 0.00 \\
$\mathbf{C l}^{-}$ & - & 0.00 & -4100.77 & -16772.53 & 0.00 & 0.00 & 0.00 & 0.00 & 0.00 \\
$\mathbf{B r}^{-}$ & - & 0.00 & -15555.29 & - & 0.00 & 0.00 & 0.00 & 0.00 & 0.00 \\
\hline
\end{tabular}

\begin{tabular}{llll}
$* \Gamma^{(1)} \mathrm{OH} / \mathrm{CH}=$ & 2629.81 & $* \Gamma^{(1)} \mathrm{CH} / \mathrm{OH}=$ & -6159.54 \\
$* \Gamma^{(1)} \mathrm{OH} / \mathrm{CH} 2=$ & -37.35 & $* \Gamma^{(1)} \mathrm{CH} / \mathrm{OH}=$ & -92.72 \\
${ }^{*} \Gamma^{(1)} \mathrm{OH} / \mathrm{CH}=$ & -201.30 & $* \Gamma^{(1)} \mathrm{CH} / \mathrm{OH}=$ & -152.30 \\
\hline
\end{tabular}




\section{Table 7c}

Values (in $\mathrm{J} / \mathrm{mol}$ ) of the non-zero NRTL-PRA group interaction parameters $\Gamma_{L K}^{(2)}($ oll $=$ methanol, ol2 $=$ ethanol) [16].

\begin{tabular}{cccc}
\hline $\mathbf{L} \backslash \mathbf{K}$ & $\mathbf{H}_{\mathbf{2}} \mathbf{O}$ & $\begin{array}{c}\mathbf{O H} \\
(\text { oll })\end{array}$ & $\begin{array}{c}\mathbf{O H} \\
(\text { ol2 })\end{array}$ \\
\hline $\mathbf{H}_{2} \mathbf{O}$ & 0.00 & -600.00 & 1274.05 \\
$\mathbf{O H}($ oll $)$ & -370.03 & 0.00 & - \\
$\mathbf{O H}($ ol2 $)$ & -2081.32 & - & 0.00 \\
\hline
\end{tabular}

\section{Table 8}

Literature data of vapor pressure $P_{v a p}$ of aqueous electrolytes: number of data points $(N)$, interval of experimental temperatures ( $T$-range in Kelvin), maximum molality $\left(m_{\max }\right)$, interval of experimental pressures ( $P$-range in bar) and references $(R e f)$.

\begin{tabular}{llccccc}
\hline Salt 1 & Salt 2 & $N$ & T-range $(K)$ & $m_{\max }$ & P-range (bar) & Ref. \\
\hline $\mathrm{NaCl}$ & - & 295 & $303-598$ & 10.41 & $0.03-118.14$ & {$[90]-[102]$} \\
$\mathrm{KCl}$ & - & 199 & $303-623$ & 4.80 & $0.04-163.97$ & {$[99],[103]-[106]$} \\
$\mathrm{LiCl}$ & - & 215 & $303-373$ & 24.65 & $0.01-0.87$ & {$[104],[107]-[109]$} \\
$\mathrm{NaBr}$ & - & 74 & $283-368$ & 10.35 & $0.01-0.79$ & $[103]-104],[110]-[111]$ \\
$\mathrm{KBr}$ & - & 66 & $283-368$ & 6.16 & $0.01-0.78$ & {$[103]-[104],[110]$} \\
$\mathrm{LiBr}$ & - & 266 & $293-530$ & 27.26 & $0.01-16.34$ & {$[104],[108],[112]-[115]$} \\
$\mathrm{NaCl}$ & $\mathrm{KBr}$ & 25 & 333.15 & 2.00 & 0.19 & {$[116]$} \\
$\mathrm{NaCl}$ & $\mathrm{KCl}$ & 48 & 343.15 & 3.35 & 0.30 & {$[117]-[118]$} \\
$\mathrm{NaBr}$ & $\mathrm{KBr}$ & 40 & 343.15 & 2.96 & 0.30 & {$[117]$} \\
$\mathrm{NaBr}$ & $\mathrm{KCl}$ & 25 & 333.15 & 2.00 & 0.19 & {$[116]$} \\
\hline
\end{tabular}

\section{Table 9}

Values of ion-specific parameter $\alpha_{k}$ in Eq. (6).

\begin{tabular}{lccccc}
\hline Ion & $\mathrm{Na}^{+}$ & $\mathrm{K}^{+}$ & $\mathrm{Li}^{+}$ & $\mathrm{Cl}^{-}$ & $\mathrm{Br}^{-}$ \\
\hline$\alpha_{k}\left(\mathrm{~m}^{3} / \mathrm{mol}\right)$ & $1.062 \times 10^{-4}$ & $8.16 \times 10^{-5}$ & $2.200 \times 10^{-4}$ & $1.173 \times 10^{-4}$ & $1.348 \times 10^{-4}$ \\
\hline
\end{tabular}




\section{Table 10}

Mean percent relative deviation $\Delta P_{v a p} / P_{v a p} \%$ on vapor pressure of aqueous electrolyte solutions with maximum molality $m_{\max }<10$. Prediction with the NRTL-PRA EoS and the new correlation for the relative permittivity of water Without (Table 5) or With (Eq. (5)) the correction factor E. Literature data: number of data points $(N)$ and maximum pressure ( $P_{\max }$ in bar).

\begin{tabular}{lcccccccccc}
\hline Salt & \multicolumn{3}{c}{$T<450 K$} & \multicolumn{5}{c}{$T>450 K$} \\
\hline & $N$ & $m_{\max }$ & $\begin{array}{c}P_{\max } \\
(\text { bar })\end{array}$ & Without $E$ & With $E$ & $N$ & $m_{\max }$ & $\begin{array}{c}P_{\max } \\
(\text { bar })\end{array}$ & Without $E$ & With E \\
\hline $\mathrm{NaCl}$ & 150 & 7.20 & 9.18 & $\mathbf{6 . 9 8}$ & $\mathbf{2 . 9 9}$ & 142 & 9.96 & 118.14 & $\mathbf{5 . 3 0}$ & $\mathbf{2 . 5 5}$ \\
$\mathrm{KCl}$ & 79 & 4.41 & 7.91 & $\mathbf{1 . 9 7}$ & $\mathbf{1 . 1 7}$ & 120 & 4.80 & 163.97 & $\mathbf{2 . 7 8}$ & $\mathbf{1 . 8 6}$ \\
$\mathrm{LiCl}$ & 96 & 9.44 & 0.87 & $\mathbf{2 7 . 8 4}$ & $\mathbf{2 . 7 3}$ & - & - & - & - & - \\
$\mathrm{NaBr}$ & 73 & 9.55 & 0.79 & $\mathbf{1 5 . 9 5}$ & $\mathbf{5 . 9 7}$ & - & - & - & - & - \\
$\mathrm{KBr}$ & 66 & 5.93 & 0.78 & $\mathbf{5 . 3 1}$ & $\mathbf{1 . 9 2}$ & - & - & - & - & - \\
$\mathrm{LiBr}$ & 78 & 9.48 & 4.57 & $\mathbf{4 6 . 6 9}$ & $\mathbf{4 . 7 4}$ & 9 & 8.97 & 18.90 & $\mathbf{4 3 . 2 0}$ & $\mathbf{3 1 . 0 7}$ \\
\hline
\end{tabular}

\section{Table 11}

Mean percent relative deviation $\Delta P_{v a p} / P_{v a p} \%$ on vapor pressure of aqueous electrolyte solutions with two electrolytes. Prediction with the NRTL-PRA EoS and the new correlation for the relative permittivity of water Without (Table 5) or With (Eq. (5)) the correction factor E. Literature data: number of data points $(N)$, maximum molality between salt 1 or salt $2\left(m_{\max }\right)$ and maximum pressure $\left(P_{\max }\right.$ in bar).

\begin{tabular}{llllcccc}
\hline Salt 1 & Salt 2 & $N$ & $m_{\max }$ & $T_{\max }(K)$ & $P_{\max }($ bar $)$ & Without $E$ & With E \\
\hline $\mathrm{NaCl}$ & $\mathrm{KBr}$ & 25 & 2.00 & 333.15 & 0.19 & $\mathbf{5 . 0 5}$ & $\mathbf{1 . 9 0}$ \\
$\mathrm{NaCl}$ & $\mathrm{KCl}$ & 48 & 3.35 & 343.15 & 0.30 & $\mathbf{3 . 9 7}$ & $\mathbf{1 . 9 6}$ \\
$\mathrm{NaBr}$ & $\mathrm{KBr}$ & 40 & 2.96 & 343.15 & 0.30 & $\mathbf{4 . 8 9}$ & $\mathbf{2 . 4 5}$ \\
$\mathrm{NaBr}$ & $\mathrm{KCl}$ & 25 & 2.00 & 333.15 & 0.19 & $\mathbf{5 . 1 0}$ & $\mathbf{2 . 0 0}$
\end{tabular}




\section{Table 12}

Mean percent relative deviation $\Delta P_{v a p} / P_{v a p} \%$ on vapor pressure of aqueous electrolyte solutions with maximum molality $m_{\max }>10$. Prediction with the NRTL-PRA EoS and the new correlation for the relative permittivity of water Without (Table 5) or With (Eq. (5)) the correction factor E. Literature data: number of data points $(N)$ and maximum pressure $\left(P_{\max }\right.$ in bar).

\begin{tabular}{|c|c|c|c|c|c|c|c|c|c|c|}
\hline \multirow[t]{2}{*}{ Salt } & \multicolumn{5}{|c|}{$T<450 K$} & \multicolumn{5}{|c|}{$T>450 K$} \\
\hline & $N$ & $m_{\max }$ & $\begin{array}{l}P_{\max } \\
\text { (bar) }\end{array}$ & Without E & With $E$ & $N$ & $m_{\max }$ & $\begin{array}{l}P_{\max } \\
\text { (bar) }\end{array}$ & Without E & With $E$ \\
\hline $\mathrm{NaCl}$ & - & - & - & - & - & 3 & 10.41 & 75.93 & 23.36 & 4.22 \\
\hline $\mathrm{LiCl}$ & 119 & 21.96 & 0.49 & 208.34 & 12.87 & - & - & - & - & - \\
\hline $\mathrm{NaBr}$ & 1 & 10.35 & 0.04 & 56.88 & 23.15 & - & - & - & - & - \\
\hline $\mathrm{LiBr}$ & 131 & 27.26 & 2.81 & 344.45 & 17.87 & 48 & 27.26 & 16.34 & 170.64 & 94.96 \\
\hline
\end{tabular}




\section{Table 13}

Mean percent relative deviations $\triangle P / P \%$ and $\triangle T / T \%$ on isothermal VLE and isobaric VLE, respectively, together with $\triangle \mathrm{y} / \mathrm{y} \%$ on the vapor phase, obtained with the NRTL-PRA EoS for alcohol-water mixtures with several salts. Literature data: intervals of experimental temperatures ( $T$-range), pressures (P-range), amount of salt introduced in the solvent mixture (m-range), type* of measurements and references (Ref.). Modeling: isothermal data, with number of pressures $\left(N_{P}\right)$ and deviations $(\triangle P / P \%)$; isobaric data, with number of temperatures $\left(N_{T}\right)$ and deviations $(\Delta T / T \%)$; vapor phase composition data, with number of points $\left(N_{y}\right)$ and deviations $(\Delta y / y \%)$.

type $^{*}$ : salt molality $(m)$, mole fraction of salt $(x)$.

\begin{tabular}{|c|c|c|c|c|c|c|c|c|c|c|c|}
\hline Salt & T-range $(\mathrm{K})$ & P-range (bar) & $m$-range & type & Ref. & $N_{P}$ & $\triangle P / P \%$ & $N_{T}$ & $\Delta T / T \%$ & $N_{y}$ & $\Delta y / y \%$ \\
\hline \multicolumn{12}{|l|}{ Methanol } \\
\hline \multirow[t]{2}{*}{$-\mathrm{NaCl}$} & $298-397$ & $0.05-4.99$ & $0-5.38$ & $\mathrm{~m}$ & [119]-[125] & 165 & 3.19 & 14 & 0.59 & 131 & 6.74 \\
\hline & $318-382$ & $0.15-1.01$ & $0-0.563$ & $\mathrm{x}$ & [126]-[127] & - & - & 17 & 0.57 & 17 & 9.41 \\
\hline \multirow[t]{2}{*}{$-\mathrm{KCl}$} & $298-373$ & $0.05-1.01$ & $0-2$ & $\mathrm{~m}$ & [119], [128] & 8 & 2.86 & 32 & 0.15 & 40 & 6.92 \\
\hline & $341-372$ & 1.01 & $0-0.105$ & $\mathrm{x}$ & [122], [129] & 36 & 4.91 & 11 & 0.77 & 47 & 10.37 \\
\hline$-\mathrm{LiCl}$ & $339-372$ & 1.01 & $1-4$ & $\mathrm{~m}$ & [128] & - & - & 47 & 0.22 & 47 & 4.86 \\
\hline \multirow[t]{2}{*}{$-\mathrm{NaBr}$} & $298-371$ & $0.06-1.01$ & $0-7.10$ & $\mathrm{~m}$ & $\begin{array}{c}{[119],[128]-} \\
{[129]}\end{array}$ & 29 & 9.45 & 23 & 0.27 & 52 & 6.20 \\
\hline & $339-373$ & 1.01 & $0-0.166$ & $\mathrm{x}$ & [122], [129] & 31 & 13.40 & 12 & 0.38 & 43 & 10.57 \\
\hline \multicolumn{12}{|l|}{ Ethanol } \\
\hline \multirow[t]{2}{*}{$-\mathrm{NaCl}$} & $298-367$ & $0.04-0.93$ & $0-1$ & $\mathrm{~m}$ & [130]-[132] & 31 & 3.94 & 28 & 0.10 & 28 & 5.22 \\
\hline & $306-367$ & $0.12-1.01$ & $0-0.347$ & $\mathrm{x}$ & $\begin{array}{c}{[126]-[128],} \\
{[131],[133]-} \\
{[134]}\end{array}$ & - & - & 96 & 1.18 & 96 & 15.45 \\
\hline$-\mathrm{KCl}$ & $298-354$ & $0.04-0.93$ & $0-3.98$ & $\mathrm{~m}$ & [129]-[130] & 23 & 3.22 & 6 & 1.26 & 6 & 20.09 \\
\hline \multirow[t]{2}{*}{$-\mathrm{LiCl}$} & $298-364$ & $0.03-0.93$ & $0.5-4$ & $\mathrm{~m}$ & [129]-[135] & 96 & 8.55 & 6 & 0.57 & 36 & 16.52 \\
\hline & $369-377$ & $0.12-0.93$ & $0.21-0.30$ & $\mathrm{x}$ & [129] & - & - & 18 & 12.02 & 18 & 80.17 \\
\hline
\end{tabular}




\section{Table 14}

Prediction of isothermal VLE provided by the NRTL-PRA EoS for methanol-water mixture with two salts at 298.15K. Literature data: intervals of experimental pressures (P-range), amount of salt introduced in the solvent mixture (m-range), type of measurements (salt molality $m$ ), references (Ref.), number of pressures $\left(N_{P}\right)$ and deviations $(\triangle P / P)$; vapor phase composition data, with number of points $\left(N_{y}\right)$ and deviations $(\Delta y / y \%)$.

\begin{tabular}{lcccccccc}
\hline Salt1+Salt2 & P-range (bar) & m-range & type & Ref. & $N_{P}$ & $\Delta P / P \%$ & $N_{y}$ & $\Delta y / y \%$ \\
\hline $\mathrm{NaCl}+\mathrm{KCl}$ & $0.07-0.08$ & $0.50-2.50$ & $\mathrm{~m}$ & {$[119]$} & 5 & 4.86 & 5 & 4.85 \\
$\mathrm{NaBr}+\mathrm{KCl}$ & 0.07 & $1-4$ & $\mathrm{~m}$ & {$[119]$} & 4 & 2.24 & 4 & 5.39 \\
$\mathrm{NaCl}+\mathrm{NaBr}$ & 0.07 & $1-4$ & $\mathrm{~m}$ & {$[119]$} & 4 & 2.20 & 4 & 5.14 \\
\hline
\end{tabular}



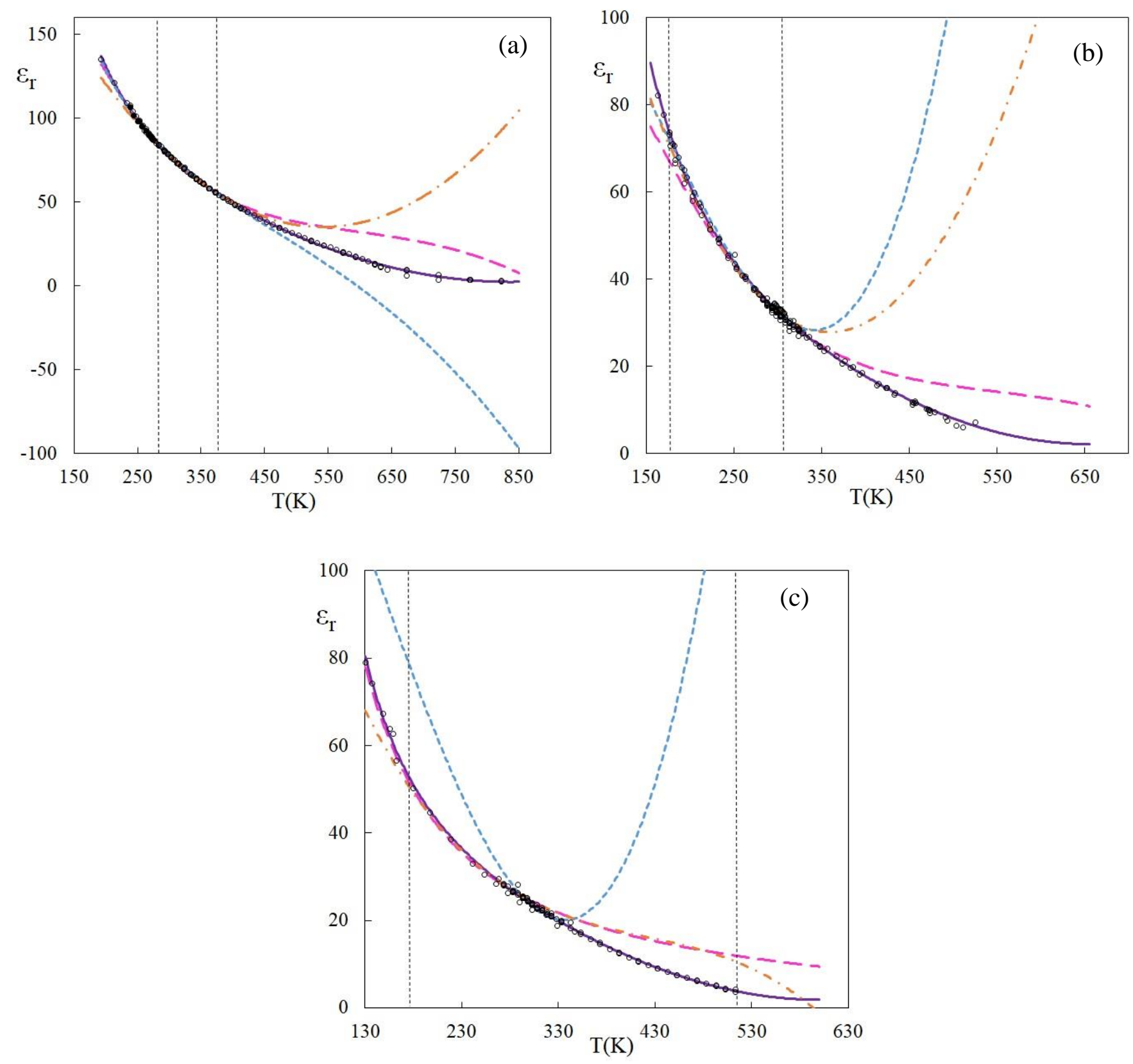

Fig. 1. Relative permittivity for (a) water, (b) methanol, (c) ethanol. Variation of $\varepsilon_{r}$ with respect to temperature obtained with: the new correlation (purple solid line), NR correlation (pink dashed line), CRC correlation (orange dash-dotted line) and ZZC correlation (blue dotted line). Circles correspond to experimental data of Table 1 and the two vertical dotted lines delimitate the temperature range of the CRC Handbook of Chemistry and Physics [24]. 

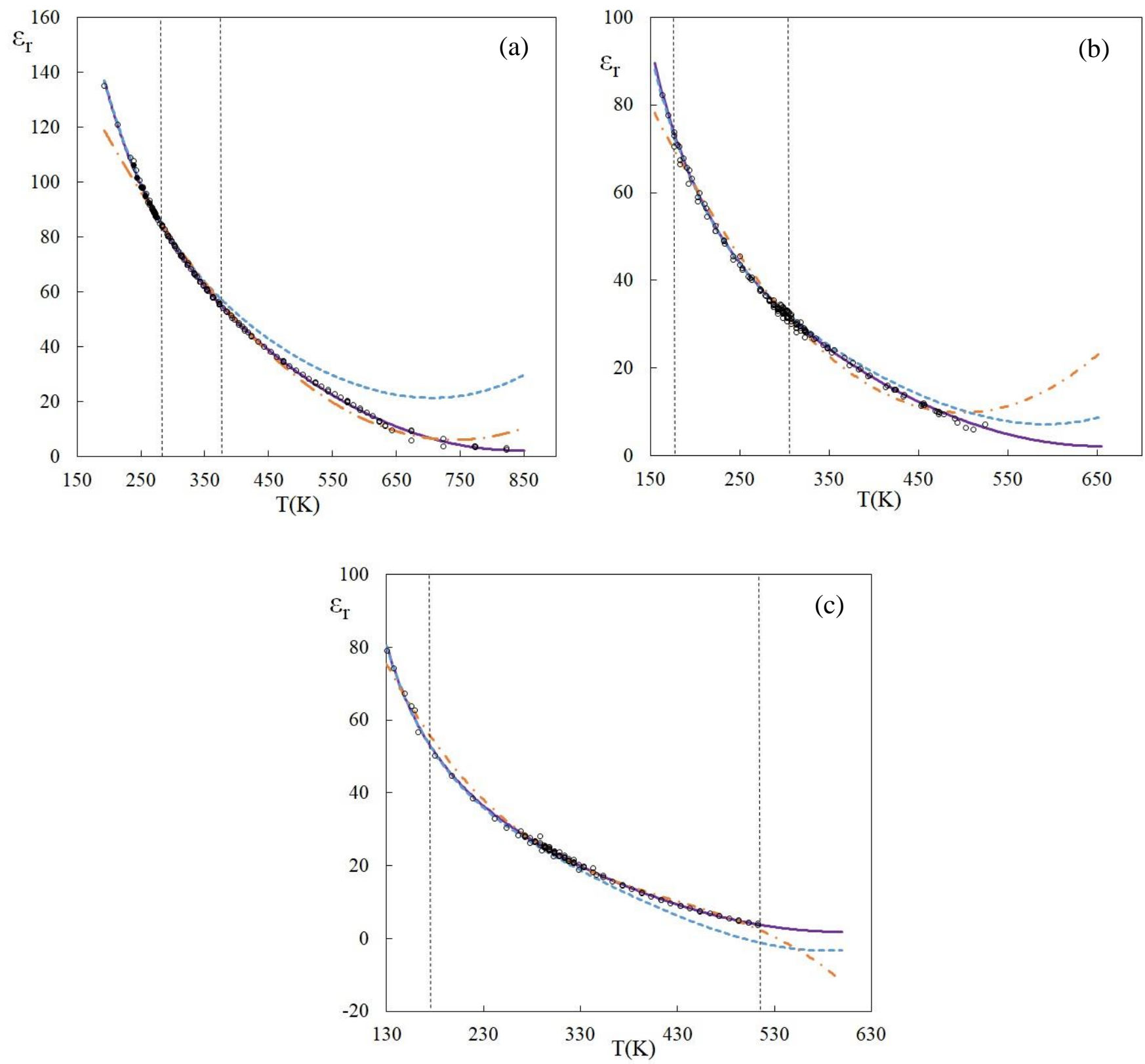

Fig. 2. Relative permittivity for (a) water, (b) methanol, (c) ethanol. Variation of $\varepsilon_{r}$ with respect to temperature obtained with the new correlation (purple solid line) and with fitted parameters for Eq. (2) (orange dash-dotted line) and Eq. (3) (blue dotted line). Circles correspond to experimental data of Table 1 and the two vertical dotted lines delimitate the temperature range of the CRC Handbook of Chemistry and Physics [24]. 

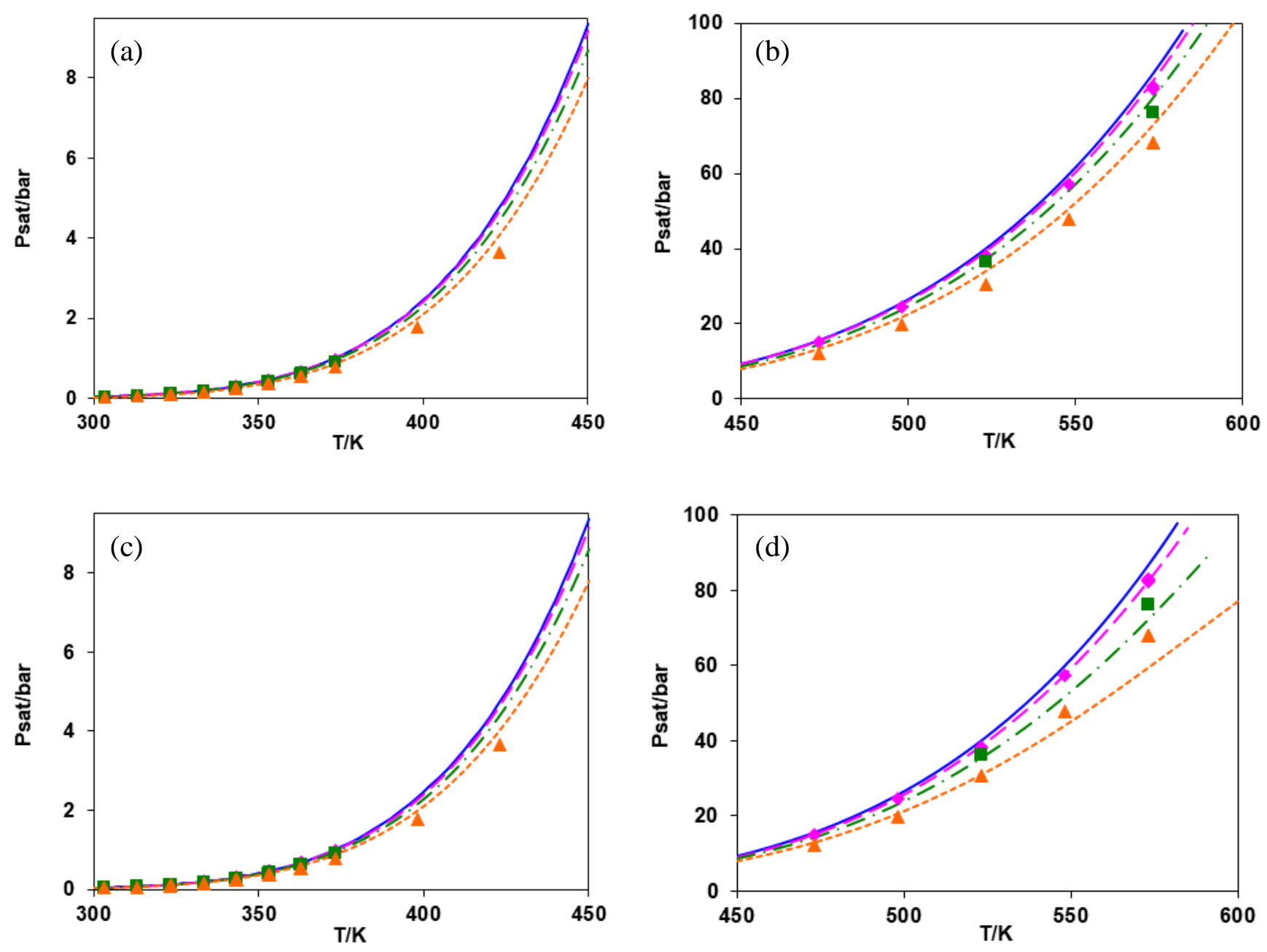

Fig. 3. Vapor pressure of water with $\mathrm{NaCl}$ for various molalities $m: \forall m=1, \square m=3, \Delta m=6$. Prediction with the NRTL-PRA EoS for $m=0$ (solid blue line), $m=1$ (dashed pink line), $m=3$ (dashdotted green line) and $m=6$ (dotted orange line) and for $\varepsilon_{r}^{*}$ in $g_{L R}^{E}$ (Table 5): the NR correlation (a, b) and the new correlation (c, d). 

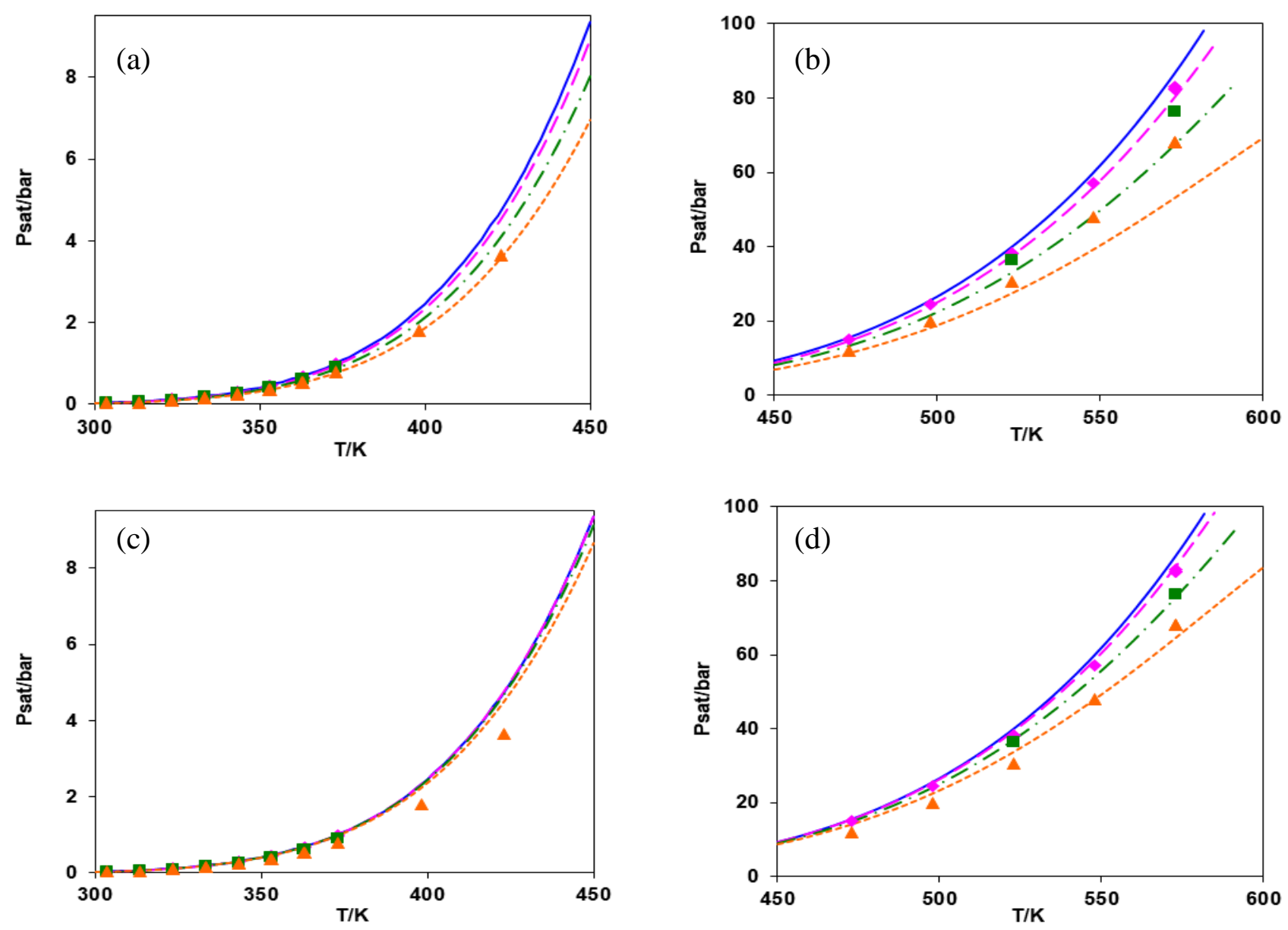

Fig. 4. Vapor pressure of water with $\mathrm{NaCl}$ for various molalities $m: \bullet m=1, \square m=3, \Delta m=6$. Calculation with the NRTL-PRA EoS by fitting binary interaction parameters $\Gamma_{\mathrm{H}_{2} \mathrm{O} / \mathrm{Na}^{+}}$and $\Gamma_{\mathrm{H}_{2} \mathrm{O} / \mathrm{Cl}^{-}}$ for $m=0$ (solid blue line), $m=1$ (dashed pink line), $m=3$ (dash-dotted green line) and $m=6$ (dotted orange line) and with the new correlation for $\varepsilon_{r}^{*}$ in $g_{L R}^{E}:(\mathrm{a}, \mathrm{b})$ Parameters fitted on data for $T$ up to $450 \mathrm{~K}\left(\Gamma_{\mathrm{H}_{2} \mathrm{O} / \mathrm{Na}^{+}}^{(0)}=-3543.75, \quad \Gamma_{\mathrm{H}_{2} \mathrm{O} / \mathrm{Na}^{+}}^{(1)}=4050.00, \quad \Gamma_{\mathrm{H}_{2} \mathrm{O} / \mathrm{Cl}^{-}}^{(0)}=-3041.30, \quad \Gamma_{\mathrm{H}_{2} \mathrm{O} / \mathrm{Cl}^{-}}^{(1)}=1013.77\right.$, $\left.\Gamma_{\mathrm{H}_{2} \mathrm{O} / \mathrm{Na}^{+}}^{(2)}=\Gamma_{\mathrm{H}_{2} \mathrm{O} / \mathrm{Cl}^{-}}^{(2)}=0\right)$; (c, d) Parameters fitted on data for $\mathrm{T}>450 \mathrm{~K}\left(\Gamma_{\mathrm{H}_{2} \mathrm{O} / \mathrm{Na}^{+}}^{(0)}=1628.80, \Gamma_{\mathrm{H}_{2} \mathrm{O} / \mathrm{Na}^{+}}^{(1)}=\right.$ -2166.91, $\left.\Gamma_{\mathrm{H}_{2} \mathrm{O} / \mathrm{Cl}^{-}}^{(0)}=1929.33, \Gamma_{\mathrm{H}_{2} \mathrm{O} / \mathrm{Cl}^{-}}^{(1)}=845.94, \Gamma_{\mathrm{H}_{2} \mathrm{O} / \mathrm{Na}^{+}}^{(2)}=\Gamma_{\mathrm{H}_{2} \mathrm{O} / \mathrm{Cl}^{-}}^{(2)}=0\right)$. 

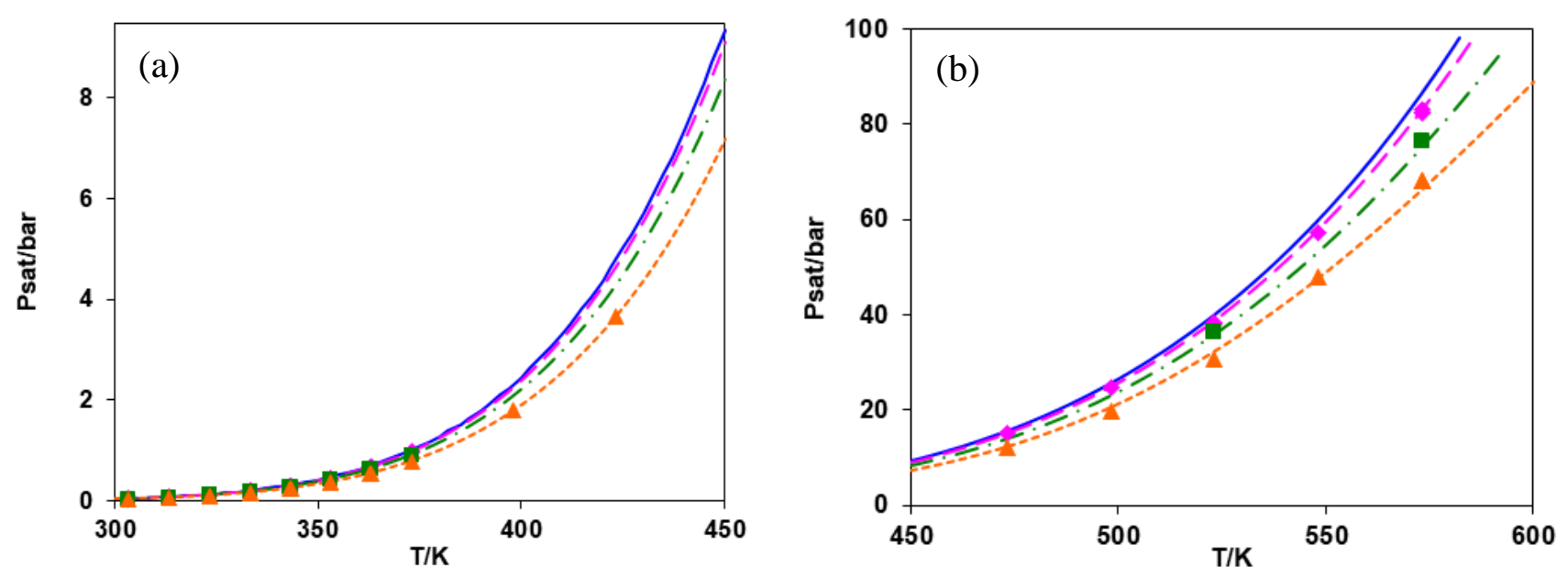

Fig. 5. Vapor pressure of water with $\mathrm{NaCl}$ for various molalities $m$ : $m=1, \square m=3, \Delta m=6$. Prediction with the NRTL-PRA EoS for $m=0$ (solid blue line), $m=1$ (dashed pink line), $m=3$ (dashdotted green line) and $m=6$ (dotted orange line) and, in $g_{L R}^{E}, \varepsilon_{r}^{*}$ calculated with Eq.(5) and the new correlation.
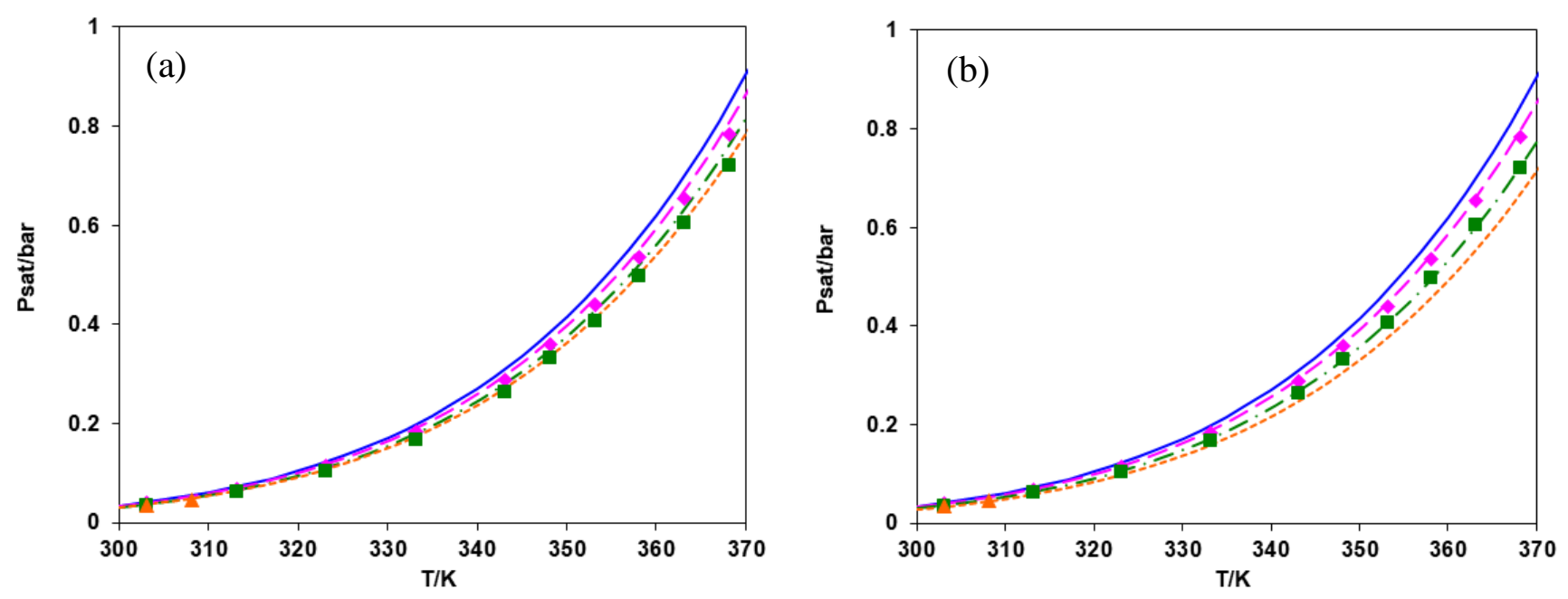

Fig. 6. Vapor pressure of water with $\mathrm{KBr}$ for various molalities $m(\diamond m=2, \square m=4, \Delta m=6)$. Prediction with the NRTL-PRA EoS for $m=0$ (solid blue line), $m=2$ (dashed pink line), $m=3$ (dashdotted green line) and $m=6$ (dotted orange line) and, in $g_{L R}^{E}, \varepsilon_{r}^{*}$ calculated with Eq.(5) and the new correlation. 

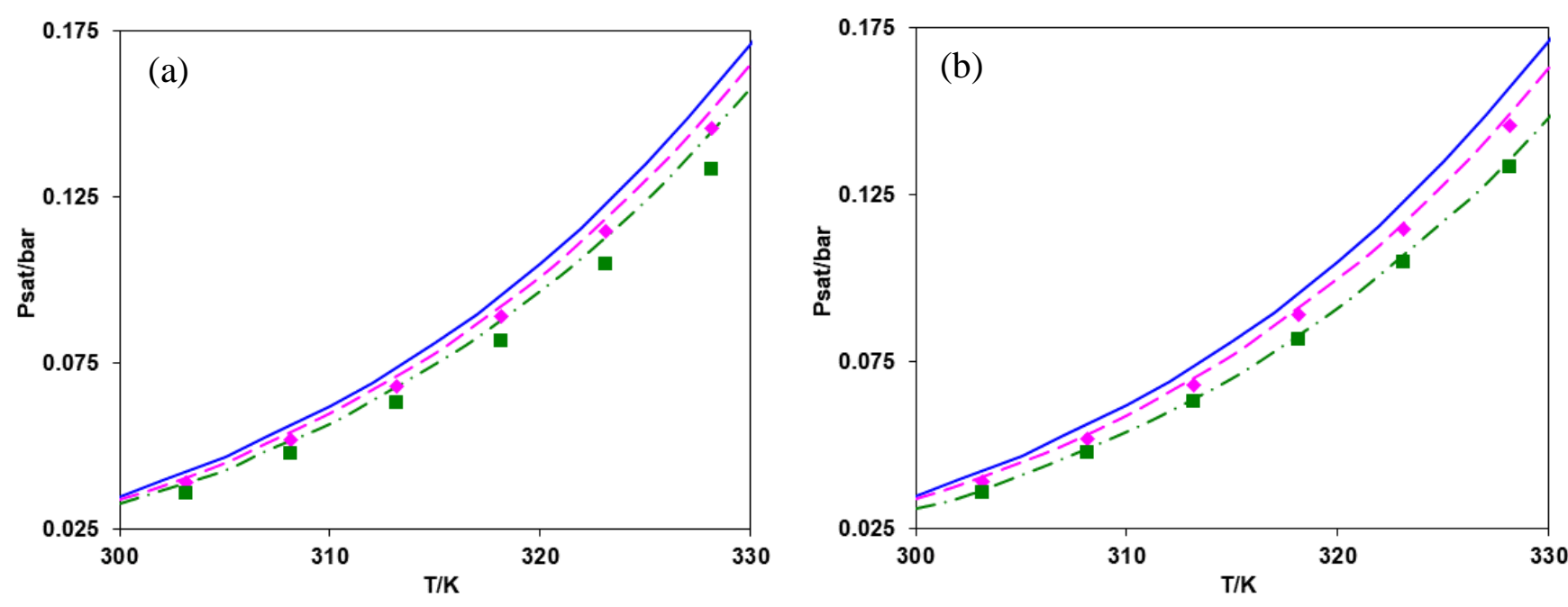

Fig. 7. Vapor pressure of water with $\mathrm{NaCl}^{1}$ and $\mathrm{KBr}^{2}$ for $m_{1}=m_{2}=1(\diamond)$ and $m_{1}=m_{2}=2(\square)$. Prediction with the NRTL-PRA EoS for $m_{1}=m_{2}=0$ (solid blue line), $m_{1}=m_{2}=1$ (dashed pink line) and $m_{1}=m_{2}=2$ (dash-dotted green line) and, in $g_{L R}^{E}, \varepsilon_{r}^{*}$ calculated with Eq.(5) and the new correlation. 

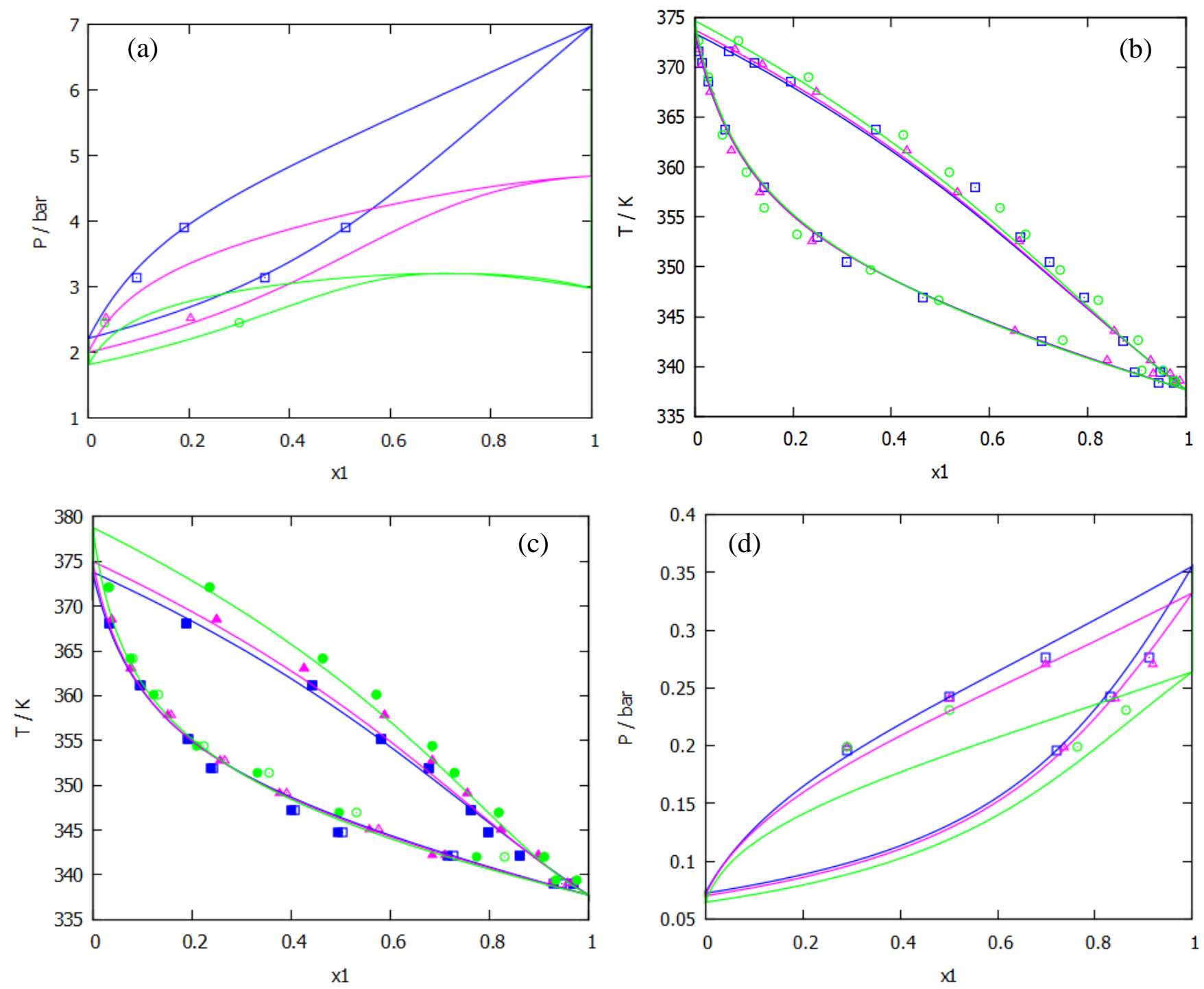

Fig. 8. VLE of methanol ${ }^{(1)}$-water ${ }^{(2)}$ with: (a) $\mathrm{NaCl}$ at $T=397 \mathrm{~K}$ for $m_{s}=0$ (๑), $m_{s}=2.76(\triangle), m_{s}=4.84(\odot)$, (b) $\mathrm{KCl}$ at $P=1.01$ bar for $m=0.5$ (घ), $m=1(\Delta), m=2$, (c) $\mathrm{LiCl}$ at $P=1.01$ bar for $m=1$ (घ, घ), $m=2(\Delta, \Delta)$, $m=4(\odot, \bullet),(\mathrm{d}) \mathrm{NaBr}$ at $T=313 \mathrm{~K}$ for $m_{s}=1(\bullet), m_{s}=2(\Delta), m_{s}=4(\odot)$. Calculation with the NRTL-PRA $\operatorname{EoS}(-)$. 

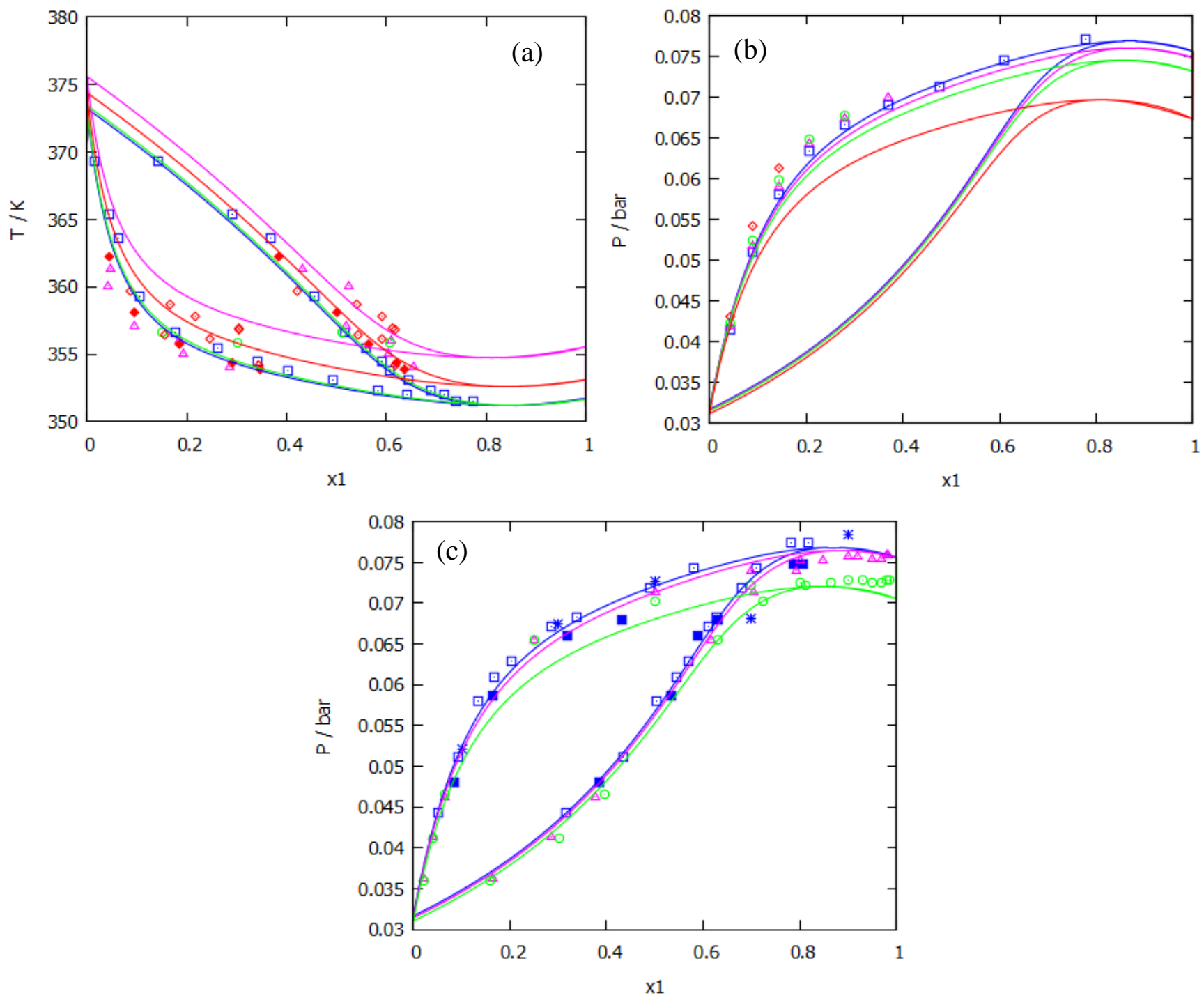

Fig. 9. VLE of ethanol ${ }^{(1)}$-water ${ }^{(2)}$ with: (a) $\mathrm{NaCl}$ at $P=1.01$ bar for $x_{\mathrm{NaCl}}=0$ (๑), $x_{\mathrm{NaCl}}=0.01(\odot)$, $x_{\mathrm{NaCl}}=0.03(\diamond, \bullet), x_{\mathrm{NaCl}}=0.05(\Delta),(\mathrm{b}) \mathrm{KCl}$ at $T=298 \mathrm{~K}$ for $m_{s}=0(\bullet), m_{s}=0.3(\Delta), m_{s}=0.5(\odot), m_{s}=1(\diamond)$, (c) $\mathrm{LiCl}$ at $T=298 \mathrm{~K}$ for $m_{s}=0(\square), m_{s}=0.5(\triangle), m_{s}=1(\odot)$. Calculation with the NRTL-PRA EoS ( - ). 